\title{
Conscious perception and the modulatory role of dopamine: no effect of the dopamine D2 agonist cabergoline on visual masking, the attentional blink, and probabilistic discrimination
}

\author{
E.A Boonstra ${ }^{1,2}$ (D) M.R van Schouwenburg ${ }^{2}$ - A.K Seth ${ }^{3,4}$ - M Bauer ${ }^{5}$ - J.B Zantvoord ${ }^{6}$. \\ E.M Kemper ${ }^{7}$. C.S Lansink ${ }^{8} \cdot$ H.A Slagter ${ }^{1,2}$
}

Received: 14 February 2020 / Accepted: 3 June 2020 / Published online: 3 July 2020

(C) The Author(s) 2020

\begin{abstract}
Rationale Conscious perception is thought to depend on global amplification of sensory input. In recent years, striatal dopamine has been proposed to be involved in gating information and conscious access, due to its modulatory influence on thalamocortical connectivity.

Objectives Since much of the evidence that implicates striatal dopamine is correlational, we conducted a double-blind crossover pharmacological study in which we administered cabergoline - a dopamine D2 agonist — and placebo to 30 healthy participants. Under both conditions, we subjected participants to several well-established experimental conscious-perception paradigms, such as backward masking and the attentional blink task.

Results We found no evidence in support of an effect of cabergoline on conscious perception: key behavioral and event-related potential (ERP) findings associated with each of these tasks were unaffected by cabergoline.

Conclusions Our results cast doubt on a causal role for dopamine in visual perception. It remains an open possibility that dopamine has causal effects in other tasks, perhaps where perceptual uncertainty is more prominent.
\end{abstract}

Keywords Dopamine - Cabergoline - Basal ganglia - Striatum · Consciousness · Backward masking · Attentional blink · Spontaneous eye blink rate $\cdot$ EEG $\cdot$ Event-related potential

E.A Boonstra

evertboonstra@gmail.com

1 Department of Experimental and Applied Psychology, Institute for Brain and Behavior Amsterdam (iBBA) Vrije Universiteit, Amsterdam, Netherlands

2 Department of Psychology, University of Amsterdam, Amsterdam Brain and Cognition $(\mathrm{ABC})$, Amsterdam, Netherlands

3 Department of Informatics Sackler Centre for Consciousness Science, University of Sussex, Brighton BN1 9QJ, UK

4 Canadian Institute for Advanced Research, Azrieli Programme on Brain, Mind, and Consciousness, Toronto, Canada

5 School of Psychology, University of Nottingham, Nottingham, UK

6 Department of Child and Adolescent Psychiatry, The Bascule, Academic Centre for Child and Adolescent Psychiatry Amsterdam University Medical Centers, Amsterdam, Netherlands

7 Department of Pharmacy, Amsterdam University Medical Centers, Amsterdam, Netherlands

8 Swammerdam Institute for Life Sciences, University of Amsterdam, Amsterdam Brain and Cognition (ABC), Amsterdam, Netherlands

\section{Introduction}

The relationship between consciousness and the brain is often lauded as one of the big mysteries in contemporary science. How does the brain constrain its own spontaneous activity as well as the influences it undergoes from outside, in the determination of conscious awareness? Several influential theories propose that consciousness is related to the "broadcasting" of sensory information to the whole brain and that thalamocortical circuits serve as an important mediator of such broadcasting (Crick \& Koch, 2003; Dehaene \& Changeux, 2011; Edelman, 2003). The broadcasting of sensory information necessitates the occurrence of selection or filtering, simply because not everything which takes place in the brain reaches conscious awareness.

With the requirement of selection, we cannot ignore the role of the basal ganglia: a cluster of subcortical nuclei located deep in the brain, which modulate activity of thalamocortical circuits (Smith et al. 2004) and have long been implicated in action selection, the decision to execute one of several 
possible behaviors (Redgrave et al. 1999). Notably, the basal ganglia are connected through parallel loops via the thalamus not only to the motor cortex, but to many parts of frontal cortex as well (Alexander et al. 1986). Hence, it is capable of modulating a wide range of cognitive operations. Indeed, the basal ganglia have been implicated in working memory updating (Frank \& O'Reilly, 2006), attention shifting (Cools, 2011), and visual categorization (Seger, 2008): cognitive acts that support suggestions concerning the common principle underlying the basal ganglia's operations; namely, selection (Frank et al. 2001; Redgrave et al. 1999).

The striatum - the biggest structure constituting the basal ganglia - deserves special attention on this topic. As the basal ganglia's primary input nucleus, the striatum is wellpositioned to play a pivotal role in the basal ganglia's selective functionalities, as terminal fields from different cortical regions converge in the striatum (Yeterian and van Hoesen, 1978; Haber et al. 2006; Mailly et al. 2013; Heilbronner et al. 2018). While dopaminergic projections are usually associated with reward prediction error (Schultz, 2016), and the role of reward in perceptual decision making (Ding \& Gold, 2013), less well-studied signaling of the (dopamine-infused) striatum include saliency, threat, processing of sensory information, and promoting of behaviors reliant on sensory information (Cox \& Witten, 2019).

Despite the suggestion that the basal ganglia may be "mute" as regards consciousness (Boly et al. 2017), it has been known for a long time that basal ganglia structures are involved in sensory and perceptual processes (Alexander \& Crutcher, 1990; Arsalidou et al. 2013; Brown et al. 1997; Seger, 2013). Both the striatum and dopaminergic firing have been implicated in the tight relationship between perception and action, and consciousness more generally. For example, dopamine-depleted mice are unable to attend to salient sensory information and choose appropriate actions, suggestive of a critical role for dopamine in the expression of consciousness (Palmiter, 2011). In humans as well, it has recently been shown that minimally conscious patients suffer from a dopaminergic deficit in presynaptic neurons projecting to the striatum and central thalamus (Fridman et al. 2019).

In humans, the striatum and its irrigation by dopamine have also been implicated in well-known experimental paradigms used to study the neural correlates of consciousness, such as the attentional blink and backward masking task. In the attentional blink task, a deficit occurs when people have to detect two target stimuli (T1 and T2) presented in close temporal succession among distracter events. Specifically, when T2 follows T1 within 100-500 ms, it often goes unnoticed. This deficit is called the attentional blink (AB) (Shapiro et al. 1997). Healthy participants with more D2-like receptor binding in the striatum - as shown with PET - showcased a larger AB (Slagter et al. 2012). In addition, intracranial EEG recordings in the ventral striatum revealed a short-latency increase in theta-band oscillatory activity only for consciously perceived target stimuli (Slagter et al. 2017).

In backward masking tasks, processing of target stimuli is interrupted by presenting a mask in close succession to the target (Breitmeyer, 2007). Studies employing fMRI consistently show differences in BOLD activity in the striatum and thalamus between seen and unseen stimuli using backward masking tasks (Bisenius et al. 2015). In another PET study, dopamine D2 binding potential in the right striatum was found to correlate positively with both objective (task performance) and subjective (seen/unseen) visibility during backward masking (Van Opstal et al. 2014). These studies collectively suggest a role for the striatum and dopaminergic activity in the selection of visual information and the formation of conscious visual percepts.

However, up until now, the relationship between striatal dopamine and conscious perception is based on correlational evidence. As such, in the present study, we sought to manipulate this relationship experimentally, by administering the dopamine D2 agonist cabergoline to healthy participants. Out of the two main dopamine receptor families, D2 receptors have been found to be more prevalent in the striatum, while D1 receptors are present more in the prefrontal cortex (Gerfen, 1992). We chose cabergoline because it has greater affinity for D2 receptors, and it has been reported to have less side effects compared to other D2 agonists such as bromocriptine (Frank \& O'Reilly, 2006). Cabergoline, at low doses, has been suggested to preferentially stimulate presynaptic D2 autoreceptors, which have been found to inhibit phasic dopamine bursts in the striatum (Ford, 2014; Frank \& O'Reilly, 2006). Cabergoline has been successfully administered in small dosages $(1-1.5 \mathrm{mg})$ to manipulate performance in healthy participants on working memory tasks (Broadway et al. 2018; Fallon et al. 2017; Frank \& O'Reilly, 2006), a modified version of the Simon task (Cavanagh et al. 2014), as well as action cancelation and error awareness tasks (Nandam et al. 2013). When cabergoline was administered to Parkinson's patients for longer periods of time, decreases in contrast sensitivity were found (Hutton et al. 1999). We administered cabergoline in an attempt to manipulate performance on two paradigms traditionally used to study the neural correlates of conscious perception: backward masking and the attentional blink task. In addition, there is increasing evidence that dopamine plays a crucial role in determining the influence of sensory information in relation to expectations acquired through past experience (Cassidy et al. 2018; Friston et al. 2012). To investigate this relationship, we subjected participants to a probabilistic discrimination task in which the probability of stimulus occurrence varied across blocks of trials, thereby tapping into the learning capabilities the basal ganglia is implicated in traditionally (Berke, 2018). 
The difficulty with manipulating dopamine is that effects have been found to depend on baseline dopamine levels in accordance with an inverted U shape (Cools \& D'Esposito, 2011). This means that dopamine is thought to have an optimal level for task performance, but that dopamine manipulations may either benefit or worsen performance dependent on an individual's starting point on the U-curve. Two measures used to estimate baseline dopamine levels are working memory operation span (OSPAN; Broadway et al. 2018; Cools et al. 2008) and spontaneous eye blink rate (sEBR; Cavanagh et al. 2014; Jongkees \& Colzato, 2016). We used these measures to analyze and control for potentially different effects of cabergoline in relation to baseline dopamine levels.

\section{Methods}

\section{Participants}

Thirty native Dutch-speakers were recruited from the University of Amsterdam subject pool to complete the experiment (mean age $=22$, range 18-29, 25 female). Because our study is the first to investigate the effects of cabergoline on conscious perception, we did not conduct a power analysis. Instead, our sample size is on the upper end of sample sizes employed by previous research in which cognitive and neural effects of cabergoline were reported with 12-30 participants (Cavanagh et al. 2014; Cohen et al. 2007; Frank \& O'Reilly, 2006; Nandam et al. 2013; Norbury et al. 2013; Yousif et al., 2016; Fallon et al. 2017; Broadway et al. 2018), and in which the behavioral and event-related potential (ERP) effects were reported which we aimed to manipulate with cabergoline (1215 subjects; Del Cul et al. 2007; van Opstal et al. 2014; Slagter et al. 2012).

Four participants experienced adverse reactions during the cabergoline session (dizziness and nausea) that interfered with their ability to participate in the study. In two participants, nausea was present to the point of vomiting. One participant dropped out due to headaches in the placebo session. Completers and non-completers did not differ in baseline age, BMI, heart rate/blood pressure, or baseline dopamine proxies (see below). It should be noted however that all drop-outs were women.

In total, 124 individuals were considered for inclusion in the study. A total of 113 were interviewed over the telephone to ensure normal or corrected-to-normal vision, no history of neurological, psychiatric, or any other relevant medical problems, and abstinence from psychoactive medication. The use of hormonal contraceptives served as an additional inclusion criterion for female participants, who were tested outside of their period due to variability in D2R availability during different phases of the menstrual cycle (Czoty et al. 2009). In total, 63 individuals were eligible for participation, out of which 35 participants were available to schedule the required three lab visits (see "Procedure"). Five participants did not meet requirements for inclusion based on the first lab visit. After excluding 5 participants with adverse reactions, the final sample consisted of 25 participants (mean age $=22$, range 18 29, 20 females). In exchange for their participation, participants received 10 euros an hour, with a minimum of 110 euros in total. The study protocol was approved by the medical ethical committee of the Academic Medical Centre, Amsterdam (currently Amsterdam University Medical Centers). All participants provided written informed consent in accordance with the Declaration of Helsinki.

\section{Procedure}

Participants came to the lab three times on different days (see Table 1). Once for screening (duration $2.5 \mathrm{~h}$ ), and twice for an experimental session in which either placebo or $1.5 \mathrm{mg}$ of cabergoline was administered orally (duration $4.5 \mathrm{~h}$ each), as part of a double-blind crossover design. Previous studies found cognitive and neural effects of cabergoline using a dosage of 1-1.5 mg (Cavanagh et al. 2014; Cohen et al. 2007; Frank \& O'Reilly, 2006; Nandam et al. 2013; Norbury et al. 2013; Yousif et al. 2016; Fallon et al. 2017; Broadway et al. 2018). As with our sample size, we chose a dosage of $1.5 \mathrm{mg}$ to be on the upper end of previously employed dosages. There was at least a day in between screening and the first session, and at least a week between both sessions.

Screening The first lab visit took place anywhere between 09:00 and 17:30. After providing written informed consent, participants answered a series of questions concerning potential medical conditions. Next, we conducted the M.I.N.I., a structured screening interview for DSM-IV axis-I disorders (Sheehan et al. 1998). We subsequently measured participant's weight, height, BMI, blood pressure (BP), and heart rate. Participants were included in the experiment only if these measures fell within pre-established bounds (BMI 18-30, diastolic $\mathrm{BP}<50$ or $>90 \mathrm{mmHg}$, systolic $\mathrm{BP}<95$ or $>$ $140 \mathrm{mmHg}$ ). Next, six external electrodes were attached to the participant's face and ears in order to measure spontaneous eye blink rate (sEBR) at rest. Finally, participants completed an operation span (OSPAN) working memory task (Unsworth et al. 2005), and a titration procedure for two behavioral tasks to be completed during both experimental sessions (backward masking and probabilistic discrimination; see below).

Session All placebo and cabergoline sessions (the second and third visit) took place between 08:30 and 14:00. Participants were instructed to abstain from drug and heavy alcohol use, the day before and during the day of the session. Also, participants were instructed to abstain from caffeine and nicotine the 
Table 1 Experimental procedures for the screening, placebo, and cabergoline sessions

\begin{tabular}{ll}
\hline Screening & Sessions (placebo/cabergoline) \\
\hline Medical questionnaire & Questions regarding recent substance use + pregnancy test \\
M.I.N.I. & Blood pressure/heart rate + VAS 1 \\
Body weight/height & Drug intake \\
Blood pressure/heart rate & 40 -min break \\
sEBR & EEG setup \\
OSPAN & sEBR \\
Titration backward masking & Blood pressure/heart rate + VAS 2 \\
Titration probabilistic discrimination & Backward masking ( $\pm 1.5 \mathrm{~h}$ after drug intake $)$ \\
& 30 -min lunch \\
& Attentional blink \\
& Reaction time task \\
& Probabilistic discrimination \\
& Blood pressure/heart rate + VAS $3( \pm 3.5 \mathrm{~h}$ after drug intake $)$ \\
\hline
\end{tabular}

morning of the session. Compliance to the instructions was checked by the examiner on arrival; in case of non-compliance, the session was postponed. Female participants completed a midstream pregnancy test. Breakfast was offered, in order to avoid cabergoline intake on an empty stomach. Blood pressure and heart rate were measured using an Omron® M3 comfort sphygmomanometer, and participants filled in a visual analog scale (VAS; see below) three times during the session: on arrival, at around $1.5 \mathrm{~h}$ after placebo or cabergoline intake, and at the end of the session. After the initial blood pressure/heart rate/VAS measurement, participants were administered either placebo or cabergoline in a double-blind fashion (order randomized across participants). After a 40min break, a BioSemi ActiveTwo system (BioSemi Inc., Amsterdam, The Netherlands) EEG cap and electrodes were fitted. Drug plasma levels have been found to reach maximum concentration after approximately 1.5-3 h (Persiani et al., 1996; Agúndez et al. 2013). Approximately $1 \mathrm{~h}$ and $20 \mathrm{~min}$ after drug intake, participants completed 6 min of sEBR recordings, followed by the backward masking task around $1.5 \mathrm{~h}$ after drug intake (see below), during which EEG was recorded. After this task, the EEG setup was removed from the participant's head. After a 30-min lunch, participants proceeded to the attentional blink task, a simple reaction time task, and the probabilistic discrimination task (see below). At the end of the experiment, one final blood pressure/heart rate and VAS measure was undertaken. At the end of the final session, participants were asked to indicate in which session they believed they had received cabergoline.

\section{Physiological and subjective state measures}

Heart rate and blood pressure Physiological measurements were taken once during screening, and three times during both sessions; namely, on arrival, at around $1.5 \mathrm{~h}$ after drug intake, and on completion of testing $( \pm 3.5 \mathrm{~h}$ after drug intake) (see Table 1). These measurements were obtained using an Omron® M3 comfort sphygmomanometer.

Subjective self-report A set of sixteen VAS measures were used (Bond and Lader 1974), to assess the subjective state of the subject before medication intake, at around $1.5 \mathrm{~h}$ after drug intake, and on completion of testing ( $\pm 3.5 \mathrm{~h}$ after drug intake). Each scale consisted of a 100-mm horizontal line, anchored by contrasting states of mind (e.g., happy versus sad). Subjects were asked to regard each line as a continuum and to rate their feelings at the time by moving a vertical slider across each line. The scales could then be scored by measuring the length in millimeters from the positive end of each line to the subject's marked location. These sixteen VAS measures were summarized as three categories: contentedness, calmness, and alertness (Bond and Lader 1974).

Baseline dopamine proxies Both sEBR and OSPAN are widely used measures that have been related to baseline dopamine levels (Cools and D'Esposito 2011; Jongkees and Colzato, 2016). Both measures have been used in combination with cabergoline in order to account for individual differences in baseline dopamine (Broadway et al. 2018; Cavanagh et al. 2014). Eye blink rate is defined as the number of spontaneous eye blinks per minute. The measure has high test-retest reliability (Kruis et al. 2016) and is an often-used biomarker of baseline dopamine D2 receptor functioning (Jongkees and Colzato 2016; Karson, 1983; Taylor et al. 1999, but see Sescousse et al. 2018). Subjects were asked to look at a central fixation cross on a computer screen in a relaxed state for $6 \mathrm{~min}$ while we measured eye activity from a set of vertical and horizontal electrodes, in order to detect eye blinks. This procedure was employed during all three lab visits. 
Eye blinks were established in two ways. First, through a fully automatic procedure implemented in the python module MNE (create_eog_epochs; Gramfort et al. 2013). Second, eye blinks were established through a custom semi-automatic procedure using EEGLAB for MATLAB (Delorme \& Makeig, 2004). If mean sEBR per minute differed more than 3 blinks between both methods, the semi-automatic procedure was repeated, and an average was taken of both semi-automatic attempts as the final value. Prior to any repetition of the semiautomatic method, correlations between the automatic and semi-automatic method exceeded .95 for measurements during all three lab visits.

OSPAN is a working memory task with high test-retest reliability (Unsworth et al. 2005), in which participants are instructed to remember letters, while solving simple arithmetic problems in between letter presentation (Unsworth et al., 2005). Sets of 3-7 letters were presented successively at fixation. The OSPAN score was calculated through partial credit scoring, so that each correctly recalled letter in the appropriate location was counted as correct, regardless of whether the entire sequence was recalled correctly or not. Scores could range from zero to 75 . OSPAN was measured only during screening.

Reaction time To assess the effects of cabergoline on alertness, we administered a 40-trial simple reaction time (RT) task (Brown et al. 2016). In this task, participants had to respond as quickly as possible by pressing the spacebar whenever a white circle (subtending approximately $3.1^{\circ}$ of visual angle) appeared at the center of the computer screen against a black background. Stimulus onset asynchrony was jittered between 500 and $1250 \mathrm{~ms}$, with a mean of $1000 \mathrm{~ms}$. This task lasted less than $2 \mathrm{~min}$.

\section{Main experimental paradigms}

All stimuli were presented on an ASUS VG236H 23-in. LCD screen $($ refresh rate $=100 \mathrm{~Hz}$, resolution $1920 \times 1080$ ) . Participants viewed the screen at a distance of $80 \mathrm{~cm}$.

Backward masking In the backward masking task, adapted from Van Opstal et al. (2014), participants had to indicate whether briefly presented masked digits $(1,4,6$, or 9) were smaller or larger than 5 and rate the confidence in their response (Fig. 1). Each trial started with the presentation of a central fixation cross ( 30 point Courier New), which increased in size (106 point Courier New, 150 ms duration), cueing the impending target. The target stimulus ( 30 point Courier New) then appeared for $10 \mathrm{~ms}$ at one of two positions centered at the vertical midline (top or bottom, $2.29^{\circ}$ from fixation). Both stimulus locations were equally probable. A mask followed the target (200 ms duration) at a variable stimulus onset asynchrony (SOA). Due to the employed refresh rate of $100 \mathrm{~Hz}$,

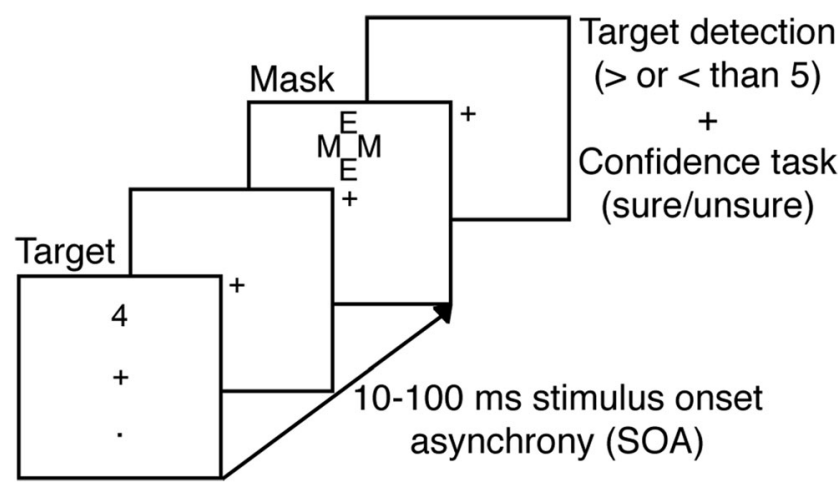

Fig. 1 Experimental procedure for one trial of the backward masking task (adapted from Van Opstal et al. 2014)

the SOA could vary from $10 \mathrm{~ms}$ to $100 \mathrm{~ms}$ in $10 \mathrm{~ms}$ steps. By making the delay between cue and target dependent on SOA, the delay between cue and mask was held constant at $800 \mathrm{~ms}$. The mask (30 point Courier New) was composed of two letters "E" and two letters " $M$ ", tightly surrounding the target location without superimposing or touching it. All stimuli were black and presented on a white background, using the Psychophysics toolbox for MATLAB (Brainard, 1997). The central fixation cross was visible throughout the experiment.

Participants were instructed to indicate by button press whether the presented digit was smaller or larger than 5 , while simultaneously indicating the confidence in their response (sure/unsure), resulting in four possible responses $(<5$ sure, $<5$ unsure, $>5$ unsure, $>5$ sure). In previous research, it was found that the D2 agonist pergolide affected response confidence (Lou et al. 2011). Responses were given by means of a response box attached to the arm rests of the participant's chair. Response buttons were counterbalanced across participants, who were instructed to guess one of two "unsure" buttons if they did not see the target.

If the participant's reaction time exceeded $1 \mathrm{~s}$, a message was presented indicating that their response was too slow for the duration of $1 \mathrm{~s}$, urging a faster response. An individual threshold for awareness was established during the screening session (see above), by fitting a logistic model (threshold defined as SOA corresponding to $75 \%$ accuracy; mean threshold $=52.93 \mathrm{~ms}, \min =31 \mathrm{~ms}, \max =89 \mathrm{~ms}, \mathrm{sd}=$ 14.38; Del Cul et al. 2006; Van Opstal et al. 2014). This model was fitted on the basis of 176 trials during screening, where each of $11 \mathrm{SOA}$ durations (from 0 to $100 \mathrm{~ms}$ ) was presented 16 times.

Prior to the experiment, participants first completed a practice block (176 trials in screening, 88 trials during placebo and cabergoline sessions). In both drug sessions, participants completed 920 trials in total, split by seven possible SOAs between target and mask: 200 mask-only trials (0 ms SOA), 200 trials each for the main SOAs $(10 \mathrm{~ms} /$ awareness threshold/100 ms), 40 trials surrounding the threshold (threshold minus $10 \mathrm{~ms}$ and threshold plus $10 \mathrm{~ms}$ ), and 40 trials with a 
$70 \mathrm{~ms}$ SOA. The trials in between individual thresholds and $100 \mathrm{~ms}$ were excluded from analysis (threshold $+10 \mathrm{~ms}$ and $70 \mathrm{~ms}$ ), because some participants arrived at an individual threshold at or above $70 \mathrm{~ms}$. This meant that trials with a SOA at threshold $+10 \mathrm{~ms}$ and $70 \mathrm{~ms}$ would fall below or above participant's individual threshold, depending on the participant. A total of 80 trials per participant were discarded for this reason, leaving 840 trials.

Attentional blink Participants also performed a standard $\mathrm{AB}$ task in which they had to identify two digits (T1 and T2) presented in a rapid stream of centrally presented distractors (letters and symbols; adapted from Slagter et al. 2012; Slagter et al., 2017; see Fig. 2). T2 followed T1 either in the time window of the $A B$, after $200 \mathrm{~ms}$ (short-interval trial), or outside the time window of the $\mathrm{AB}$, after $800 \mathrm{~ms}$ (long-interval trial). Each trial started with a central fixation cross $(1500 \mathrm{~ms})$, after which the stimulus stream began, consisting of 22 stimuli. Stimuli were presented on a black background (RGB 70, $70,70)$ at the center of the screen (28 point Arial; $0.85^{\circ}$ visual angle) for $50 \mathrm{~ms}$, followed by a $50 \mathrm{~ms}$ blank. Digits were drawn randomly (without replacement) from the set 2-9. Distractors were randomly drawn (without replacement) from the following set of 30 letters and symbols: $\mathrm{W}, \mathrm{E}, \mathrm{R}, \mathrm{T}, \mathrm{Y}, \mathrm{U}$, P, A, D, F, G, H, J, K, L, Z, X, C, V, B, N, M, @, \#, \$, \%, \}, \&, $<$, and $=$. Participants were asked to indicate sequentially the identity of the targets they saw, using the numpad on a standard keyboard. If they missed a target, they were instructed to guess. Stimulus presentation was performed using Presentation (Neurobehavioural Systems).

In both sessions, participants first completed a short practice block (20 trials), in which the first 8 trials moved at half speed. Next, participants moved on to the main experiment (222 trials), spread over 6 blocks consisting of 37 trials each.

Probabilistic discrimination In the probabilistic discrimination task, adapted from Bauer et al. (2016, September), participants were presented continually with a central fixation cross $(28$ point Arial, RGB $0,0,0)$, on top of which an image $\left(6.68^{\circ}\right.$

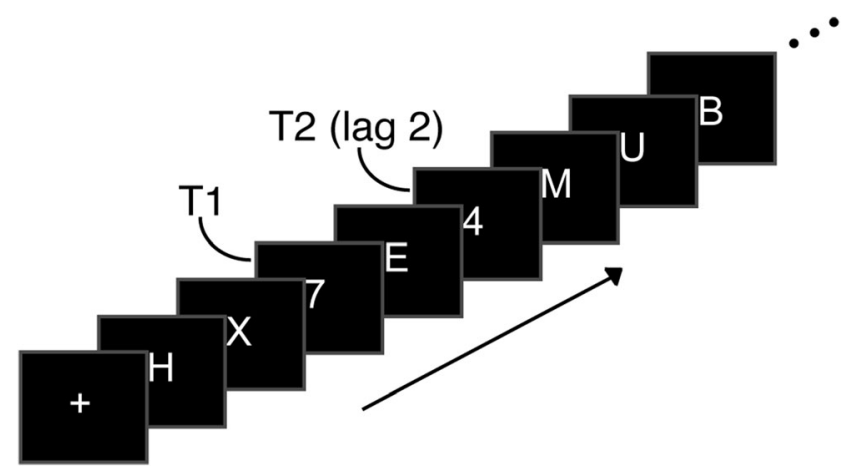

Fig. 2 Experimental procedure for one trial of the attentional blink task (adapted from Slagter et al., 2017) visual angle) of either a face or house was presented for $120 \mathrm{~ms}$, against a gray background (RGB 128, 128, 128). Face stimuli were created on the basis of the Park Aging Mind Laboratory, University of Texas at Dallas (Minear \& Park, 2004), while house stimuli were based on the Caltech University Computational Vision database (http://vision. caltech.edu/archive.html). On each trial, participants had to report the category of the image with by pressing "Q" or "P" on a standard keyboard. Responses were counterbalanced across participants, who were instructed to emphasize accuracy over and above speed. The maximum response interval was $1700 \mathrm{~ms}$, after which the next stimulus was presented regardless of whether a response was given. The inter-trial interval was jittered and varied from 800 to $1200 \mathrm{~ms}$.

The difficulty of stimulus discrimination was manipulated in terms of stimulus coherence (Fig. 3). Stimuli from the abovementioned databases were cropped to the outlines of faces and houses, and a 2-dimensional spatial Fourier transform (on luminance values for $x$ - $/ y$-coordinates) was calculated. The amplitude (power-) spectra of all 82 face and house images were averaged and subsequently applied to all individual images, such that all images (faces and houses of all coherence levels) had an identical power spectrum. In other words, none of them differed in global contrast or luminance. The phase-spectra of each individual image (that therefore provided all pictorial information) was retained and was subsequently superimposed with various levels of (uniform) random noise for each image (Bauer et al. 2016, September). To account for bias in the circular phase distribution of superimposed noise and signal phase-spectra, noise-spectra were sampled following previous suggestions (Dakin et al. 2002).

Titration consisted of two subsequent procedures, in order to establish three difficulty levels for each individual participant. First, participants completed 300 trials, spread over 10 staircase blocks, in order to establish difficulty levels corresponding to an accuracy of $75 \%$ for each stimulus category separately. During this 3-up-1-down staircase procedure, participants received a green thumbs-up (RGB R [56,154 79], border RGB [17 79 22]) or red thumbs-down (RGB [83 2 5], border RGB [251 84 84]) at the center of the screen as feedback after each trial (500 ms duration).

Next, a total of 810 trials followed, across 27 blocks, in order to extrapolate the acquired difficulty level to three difficulty levels. For the second part of the titration procedure, participants received feedback in the break in between blocks, in order to counteract the development of a bias for one of two response categories. Difficulty levels were estimated using the method of constant stimuli (MOCS; Bauer et al. 2016, September). The psychometric functions obtained through this procedure were used to estimate difficulty (coherence) levels corresponding to 70,82 , and $95 \%$ accuracy. 
Fig. 3 Probabilistic discrimination stimuli (adapted from Bauer et al., 2016, September)
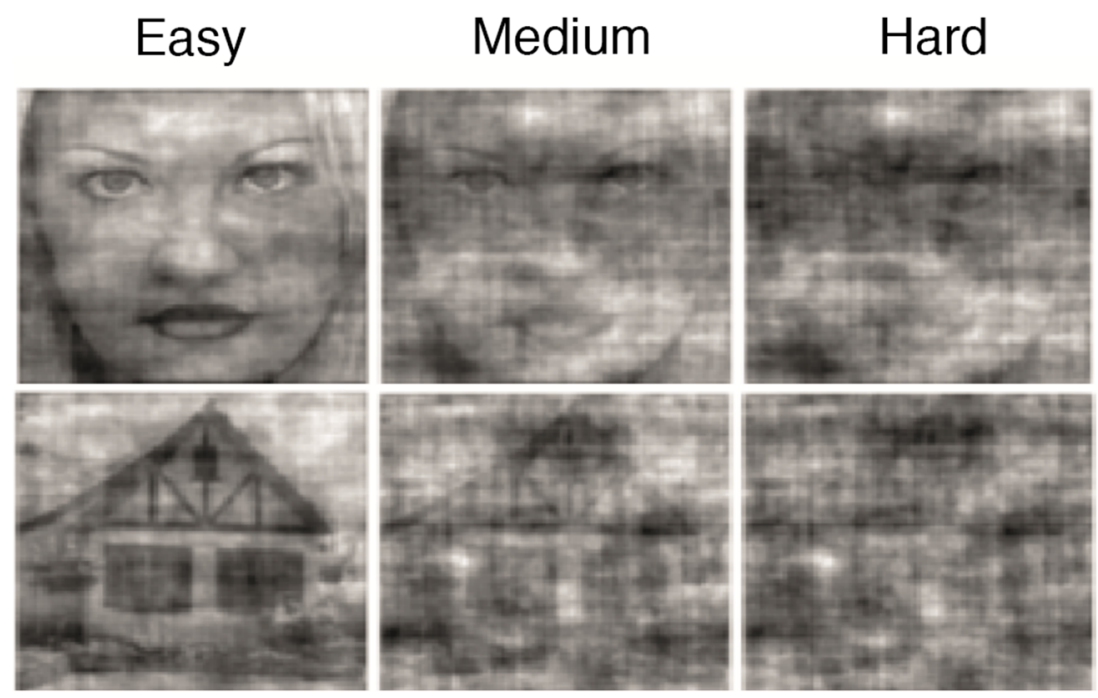

In both the placebo and cabergoline session, the same three difficulty levels were employed that were acquired from the titration procedure during screening. Unbeknownst to participants, the prior probability of each category was manipulated in a block-wise manner $(20 / 35 / 50 / 65 / 80 \%)$, spread over 25 blocks of 40 trials each, for a total of 1000 trials per session. As such, we manipulated perceptual information (difficulty) and stimulus prior probability independently of one another. Stimulus presentation for the titration procedure during the screening was performed using the Psychophysics toolbox for MATLAB (Brainard 1997), and Presentation was used to present the task in both experimental sessions (Neurobehavioural Systems).

\section{Behavioral analyses}

Physiological and subjective state measures In order to test whether physiology and subjective state changed over the course of the experiment, and whether these measures were influenced by cabergoline, we conducted a repeated-measures analysis-of-variance (RM ANOVA) for heart rate, diastolic and systolic blood pressure, and each VAS category separately, across all three time-points and both sessions. We conducted a paired-samples $t$-test between sessions for our simple RT task, as an additional measure to assess alertness. In order to test whether cabergoline exerted influence on SEBR, we conducted a paired-samples $t$-test between SEBR under placebo versus cabergoline. Kendall's Tau correlation was employed to establish the relationship between sEBR sessions, as well as the relationship between sEBR and OSPAN, as this coefficient is more robust in the case of small samples and tied ranks (Bonett and Wright 2000). Correlations were Bonferroni corrected for multiple comparisons.

Backward masking The dependent measures in the backward masking task were accuracy (0/1) and confidence (unsure/ sure). For both of these measures, we computed a 2 (Drug; placebo/cabergoline $) \times 5(\mathrm{SOA}$; mask-only $/ 10 \mathrm{~ms} /$ threshold$10 \mathrm{~ms} /$ threshold/100 ms) RM ANOVA. Furthermore, we performed an additional analysis including screening sEBR and OSPAN as covariates in both of these analyses, as we predicted cabergoline effects may depend on individual baseline dopamine levels, based on previous reports (Broadway et al., 2018; Cavanagh et al. 2014; Cools and D'Esposito, 2011; Jongkees and Colzato, 2016). We repeated these analyses for the two-alternative forced choice version of the signal detection theory parameters d' (Green and Swets 1966) and meta-d' (Maniscalco and Lau 2012), for the three primary SOAs (10 ms, threshold, and $100 \mathrm{~ms}$ ).

One participant confused the confidence response buttons in one session. We reversed these confidence scores manually. One participant experienced side effects only near the end of the last session. This participant thus completed the backward masking task twice without knowledge about drug condition. In order to maximize statistical power, this participant was included in all analyses concerning the backward masking task (including EEG), but not in the analyses of other tasks. It did not matter for our results whether this participant was included in the backward masking task analyses or not.

Attentional blink The dependent measures for the $\mathrm{AB}$ task were T1 accuracy and T2 | T1 accuracy. In other words, T2 accuracy was based only on those trials where T1 was correctly reported. For each of these measures, we computed a 2 (Drug; placebo/cabergoline) $\times 2$ (Lag; 2/8) RM ANOVA. For this task as well, we computed additional analyses in order to include sEBR and OSPAN as covariates. Finally, we computed AB size, in order to investigate the relationship between $\mathrm{AB}$ size and our baseline dopamine measures as some (Colzato et al. 2008) but not other studies (Slagter et al. 2012) have found. 
Probabilistic discrimination In the case of the probabilistic discrimination task, our dependent measure of interest was accuracy. As such, we computed a 2 (Drug; placebo/ cabergoline $) \times 3$ (Difficulty; easy/medium/hard $) \times 5$ (Probability; .2/.35/.5/.65/.8) RM ANOVA. For this analysis as well, we computed additional models including screening sEBR and OSPAN as covariates.

Our titration procedure was not successful for all participants. As a result, a number of participants ended up with only two difficulty levels for one out of two stimuli. For this reason, we repeated the above analysis for both the group with all difficulty levels $(N=16)$, and participants who had either two or three difficulty levels as a result of the titration procedure $(N=24)$. In this latter analysis, we excluded the mediumdifficulty trials. One participant was excluded from both analyses, because this participant ended up with only one difficulty level for face stimuli.

All covariates in the abovementioned RM ANOVAs were centered (van Breukelen and van Dijk 2007). For all repeatedmeasures ANOVA analyses, whenever Mauchly's test suggested a violation of sphericity, we report GeenhouseGeisser corrected $P$ values, but uncorrected degrees of freedom. In order to test for order effects, we repeated each of the RM ANOVAs for our behavioral paradigms including a between-subject factor indicating whether a participant received either placebo or cabergoline in the first session.

Bayesian statistics In order to evaluate evidence in favor of our (null) hypotheses, we conducted Bayesian statistics. For each reported frequentist test, we report the Bayes factor corresponding to the inclusion of a factor or interaction within the model in question (shortened to $\mathrm{BF}_{\text {incl }}$ ), compared to equivalent models stripped of the effect. For example, $\mathrm{BF}_{\text {incl }}=10$ indicates that a model including the factor in question is ten times more likely given the data compared to a model without the variable. Conversely, $\mathrm{BF}_{\text {incl }}=.1$ indicates that a model without said effect is ten times more likely given the data. All Bayesian statistics were conducted using JASP (JASP Team, 2019, version 0.10.0).

All data visualization was performed with the help of raincloud plots (Allen et al. 2019), which include the mean, individual data points, as well as the overall distribution of the measure in question.

\section{EEG}

Recording and preprocessing EEG data, digitized at $512 \mathrm{~Hz}$, were continuously recorded in both the placebo and cabergoline session during 6 min of sEBR and the backward masking task, using an ActiveTwo system (BioSemi, Amsterdam, the Netherlands), from 64 scalp electrodes placed according to the 10/20 system, four electro-oculographic electrodes placed above and below, and to the side of the eyes, and two external electrodes attached to each earlobe. EEG data were offline referenced to the average activity recorded at the earlobes, and high-pass "firws" filtered (default settings) at $0.05 \mathrm{~Hz}$ using a Kaiser window, following previous suggestions (Widmann et al. 2015). The continuous data were subsequently epoched from -1.5 to $1.5 \mathrm{~s}$ around stimulus presentation and baseline corrected to the average activity between $-200 \mathrm{~ms}$ and $0 \mathrm{~ms}$ pre-stimulus. Epochs containing EMG artifacts or eye blinks surrounding stimulus presentation were rejected based on visual inspection. Extremely noisy or broken channels were interpolated. Remaining eye blink artifacts were removed by decomposing the EEG data into independent sources of brain activity using an independent component analysis, and removing eye blink components from the data for each subject individually. Epochs were low-pass filtered at $30 \mathrm{~Hz}$ for visualization purposes only. Preprocessing was done using the Fieldtrip toolbox (Oostenveld et al. 2011) for Matlab (The MathWorks, Inc. Natick, MA, USA) using custom-written Matlab scripts.

Analyses To determine the effect of our manipulations on ERP markers of information processing, we examined the effects of SOA and drug on the amplitude of the visualevoked P1 and N1 components, the N2, as well as of the later P3b (Del Cul et al. 2007). In line with Del Cul et al. (2007), we epoched the ERP data to the onset of the mask. Next, we subtracted the data from the mask-only SOA condition from all other SOA conditions. Finally, we shifted ERP onset back to target onset, in order to compute target-locked ERPs. Visual inspection of the grandand condition-average ERPs showed that the P1 and N1 components peaked over lateral occipitoparietal scalp sites (PO7, PO3, O1, PO4, PO8, O2), the $\mathrm{N} 2$ over centroparietal scalp regions $(\mathrm{C} 1, \mathrm{Cz}, \mathrm{C} 2, \mathrm{CP} 1, \mathrm{CPz}$, $\mathrm{CP} 2$ ), and the $\mathrm{P} 3 \mathrm{~b}$ over central parietal scalp sites (P1, $\mathrm{Pz}, \mathrm{P} 2, \mathrm{PO} 3, \mathrm{POz}, \mathrm{PO} 4)$. These scalp sites were used to determine the peak amplitude and latency of these components for each condition of interest. Specifically, the largest positive voltage value between 75 and $150 \mathrm{~ms}$ posttarget, and the largest voltage negativity within 150 $225 \mathrm{~ms}$ were selected to determine the amplitude and latency of the P1 and N1 peaks, respectively, for each subject separately. In the case of the P2 and N2, these intervals were $175-250 \mathrm{~ms}$, and $250-375 \mathrm{~ms}$, respectively. For the P3, an interval of 300-450 ms was used. All average amplitude values $15 \mathrm{~ms}$ around the peak sample, as well as individual latencies, were entered into separate RM ANOVAs with two within-subject factors: SOA $(10 \mathrm{~ms}$, threshold $-10 \mathrm{~ms}$, threshold, $100 \mathrm{~ms}$ ) and drug (placebo/ cabergoline). Because the mask-only condition is used to acquire ERP data for the remaining four SOA conditions (see above), the SOA factor contains four instead of five levels for ERP analyses. 


\section{Results}

\section{Physiological and subjective state measures}

First, we aimed to establish whether cabergoline exerted physiological effects (Fig. 4). Heart rate decreased over time in both placebo and cabergoline conditions $\left(\mathrm{F}_{(2,48)}=11.8\right.$, $\left.p<.001, \eta^{2}=.06, \mathrm{BF}_{\text {incl }}>100\right)$ and was overall higher in the cabergoline condition $\left(\mathrm{F}_{(1,24)}=9, p=.006, \eta^{2}=.03, \mathrm{BF}_{\text {incl }}=\right.$ 57.3), but there was no interaction between time and $\operatorname{drug}\left(\mathrm{F}_{(2}\right.$, ${ }_{48)}<1, p=.63, \mathrm{BF}_{\text {incl }}=.14$; see Fig. $4 \mathrm{a}$ ). In the case of diastolic blood pressure as well, we also observed a decrease over time $\left(\mathrm{F}_{(2,48)}=21.7, p<.001, \eta^{2}=.14, \mathrm{BF}_{\text {incl }}>100\right)$, but in this case, an overall lower measurement in the cabergoline condition $\left(\mathrm{F}_{(1,24)}=9.9, p=.004, \eta^{2}=.03, \mathrm{BF}_{\text {incl }}=12.4\right)$, and again no interaction between time and drug $\left(\mathrm{F}_{(2,48)}<1\right.$, $\left.p=.42, \mathrm{BF}_{\text {incl }}=.2\right)$. With regard to systolic blood pressure, we also observed a decrease in blood pressure over time $\left(\mathrm{F}_{(2}\right.$, $\left.{ }_{48)}=36.7, p<.001, \eta^{2}=.22, \mathrm{BF}_{\text {incl }}>100\right)$ and an overall lower measurement in the cabergoline condition $\left(\mathrm{F}_{(1,24)}=9\right.$, $p=.006, \eta^{2}=.03, \mathrm{BF}_{\text {incl }}=31.2$ ), but here a significant interaction between time and drug was found $\left(\mathrm{F}_{(2,48)}=7.2\right.$, $p=.002, \mathrm{BF}_{\text {incl }}=5.8$; see Fig. $4 \mathrm{~b}$ ). Thus, all three physiological measures decreased over time. While heart rate was higher, and diastolic blood pressure lower across the cabergoline session, cabergoline can only be said to have decreased systolic blood pressure, as indicated by the interaction between time and drug.

Cabergoline also affected the subjective state of participants over the course of the experiment, as indicated by the VAS (visual analog scale, see Fig. 5). On the calmness scale, there was no main effect of drug $\left(\mathrm{F}_{(1,24)}<1, p=.63\right.$, $\mathrm{BF}_{\text {incl }}=.23$ ), but calmness increased over the course of the experiment $\left(\mathrm{F}_{(2,48)}=14.5, p<.001, \eta^{2}=.04, \mathrm{BF}_{\text {incl }}=31\right)$. In addition, we found an interaction between drug and time $\left(\mathrm{F}_{(2}\right.$, $\left.{ }_{48)}=5.8, p=.005, \eta^{2}=.02, \mathrm{BF}_{\text {incl }}=2\right)$, reflecting the fact that calmness ratings increased less in the cabergoline condition (Fig. 5). In the case of contentedness, there was no main effect of drug $\left(\mathrm{F}_{(1,24)}<1, p=.46, \mathrm{BF}_{\text {incl }}=.3\right)$, time $\left(\mathrm{F}_{(2,48)}=2.7\right.$, $p=.08, \mathrm{BF}_{\text {incl }}=.33$ ), or an interaction between drug and time
$\left(\mathrm{F}_{(2,48)}<1, p=.53, \mathrm{BF}_{\text {incl }}=.16\right.$; see Fig. 5). Finally, alertness decreased over the course of the experiment $\left(\mathrm{F}_{(2,48)}=10.3\right.$, $p=.001, \eta^{2}=.12, \mathrm{BF}_{\text {incl }}>100$ ) and was generally lower in the cabergoline session compared to placebo session $\left(\mathrm{F}_{(1,24)}=\right.$ $\left.6.3, p=.02, \eta^{2}=.01, \mathrm{BF}_{\text {incl }}=1.1\right)$, but there was no interaction $\left(\mathrm{F}_{(2,48)}=1.8, p=.18, \mathrm{BF}_{\text {incl }}=.21\right.$; see Fig. 5). Thus, cabergoline decreased self-reported ratings of calmness and alertness as the experiment progressed.

In total, $85 \%$ of participants successfully guessed when they received cabergoline at the end of the experiment. However, despite these effects, we found no significant difference in SEBR (spontaneous eye blink rate) between placebo $(\mathrm{M}=14$ blinks per minute, $\mathrm{SD}=8.9)$ and cabergoline $(\mathrm{M}=$ $15.3, \mathrm{SD}=10.6)\left(t_{(24)}=-1.2, p=.23, \mathrm{BF}_{01}=.41\right)$. In addition, we were unable to replicate the finding by Cavanagh et al. (2014) that baseline sEBR conditioned a cabergolineinduced shift in line with an inverted-U-shape pattern, to the point where high baseline sEBR (as indicative of high tonic striatal dopamine) is associated with a reduction in blink rate, whereas low baseline sEBR is linked to an increase in blink rate: we found that the difference in SEBR between drug conditions was unrelated to screening $\mathrm{SEBR}(\mathrm{M}=13.2, \mathrm{SD}=7.8)$ $\left(\tau_{(25)}=.23, p=.11\right)$.

Replicating previous findings (Jongkees and Colzato, 2016; Kruis et al. 2016), sEBR was correlated across sessions: between the placebo and cabergoline session $\left(\tau_{(25)}=.63\right.$, $p<.001)$, between the screening and cabergoline session $\left(\tau_{(25)}=.37, p=.01\right)$, as well as between the screening and placebo session $\left(\tau_{(25)}=.32, p=.03\right.$; see Fig. $\left.6 \mathrm{a}\right)$. The latter two correlations did not survive a Bonferroni correction for multiple comparisons using a corrected alpha level of .05/ $6=.0083$, based on all correlations computed in this section. Together these results lend support to the robustness of the measure when measured at the same time of day (Barbato et al. 2000; Jongkees and Colzato, 2016). However, despite the proposed relation between sEBR and OSPAN as a biomarker of striatal dopamine, we found no relationship between these measures in either the cabergoline $\left(\tau_{(25)}=.06\right.$, $p=.67)$ or placebo session $\left(\tau_{(25)}=.06, p=.67\right)$. This relationship was absent even when these measures were collected in

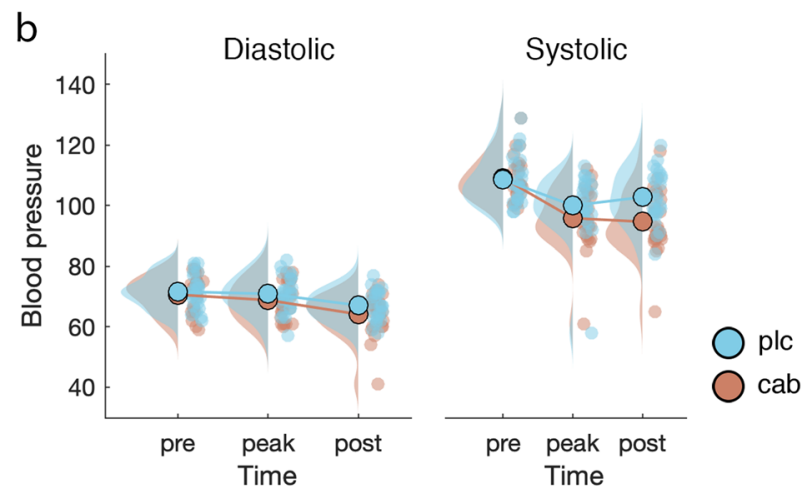

Fig. 4 Time course and difference between drug conditions in heart rate and blood pressure. All three physiological measures decreased over time. Cabergoline only affected systolic blood pressure, while heart rate was higher and diastolic pressure was lower in the cabergoline versus placebo session

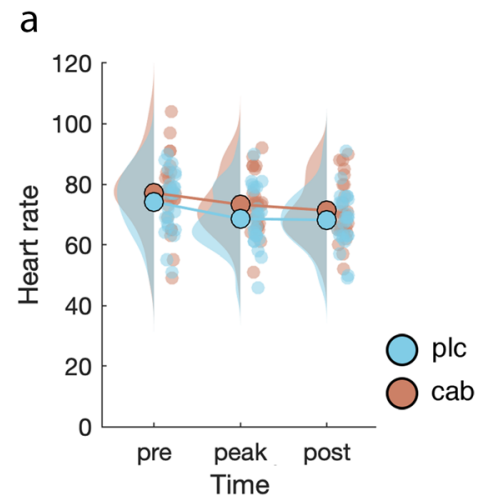


Fig. 5 Time course and difference between drug conditions in VAS scores for calmness, contentedness, and alertness. Participants become calmer and less alert over the course of the experiment. Cabergoline stifled this increase in calmness

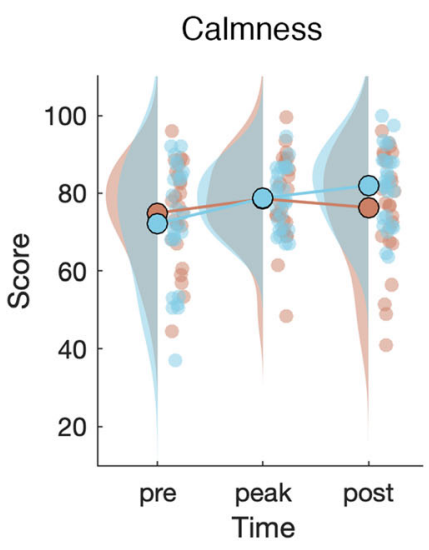

Contendedness

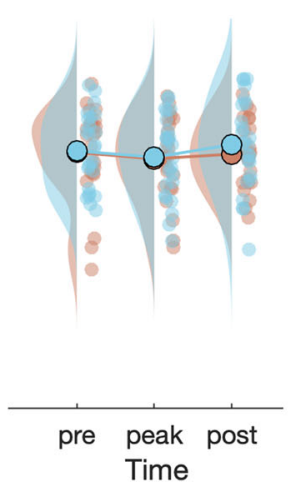

Alertness

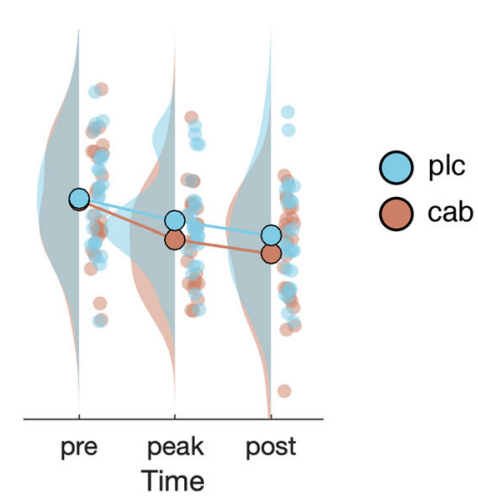

the same session; namely, during screening $\left(\tau_{(25)}=-.11\right.$, $p=.47$; see Fig. 6b). Finally, alertness, as indicated by our simple RT task, also did not differ between the placebo $(\mathrm{M}=224 \mathrm{~ms}, \mathrm{SD}=15.8)$ and cabergoline condition $(\mathrm{M}=$ $225 \mathrm{~ms}, \mathrm{SD}=15.1)\left(t_{(25)}=-.54, p=.59\right)$.

Thus, cabergoline did not affect sEBR or our objective measure of alertness.

\section{Main experimental paradigms}

We next examined potential effects of cabergoline on our main experimental measures of interest: target identification accuracy and processing in the backward masking task, attentional blink size in the attentional blink task, and discrimination accuracy under varying conditions of difficulty and probability in the probabilistic discrimination task. To foreshadow our results, cabergoline did not affect any of the key behavioral findings associated with these tasks, whether sEBR or OSPAN was included as covariates in the analyses or not. Neither did it affect neural processing of the target in the backward masking task, as shown by ERP analyses. Yet, importantly, we did replicate all standard findings typically obtained with these tasks (e.g., effects of masking on targetevoked ERPs, the attentional blink).

\section{Backward masking}

Behavior As is typically observed (e.g., Breitmeyer, 2007) and shown in Fig. 7, targets were more often identified correctly in the backward masking task as the delay between target and mask $(\mathrm{SOA})$ increased $\left(\mathrm{F}_{(4,100)}=187.4, p<.001, \eta^{2}=.79\right.$, $\left.\mathrm{BF}_{\text {incl }}>100\right)$. Yet, in contrast to our main prediction that
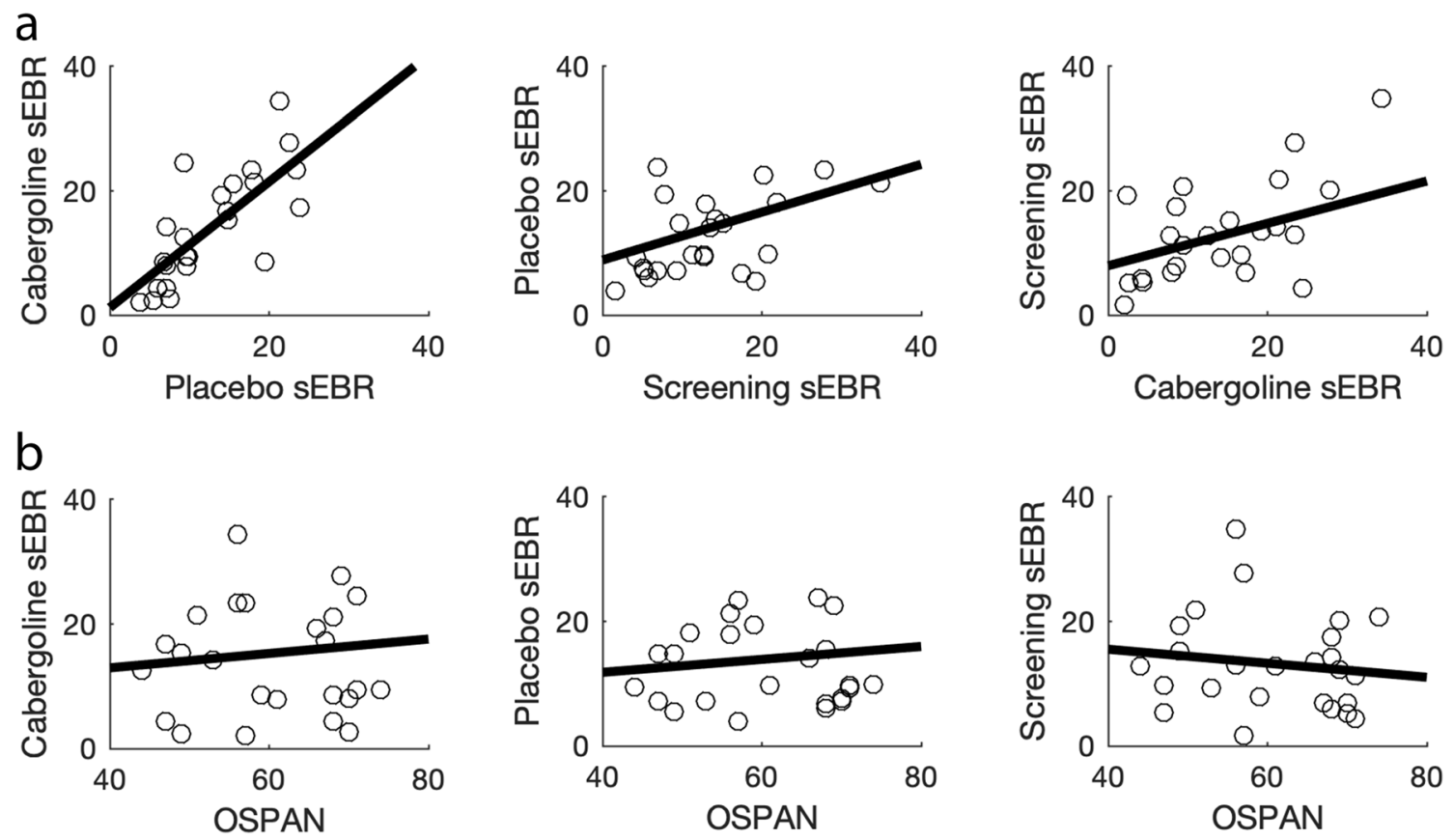

Fig. 6 The relationship between sEBR measures among themselves and in relation to OSPAN. All sEBR measures were found to be positively correlated (a), but we found no relationship between SEBR and OSPAN (b) 
Fig. 7 Mean accuracy and confidence scores in the backward masking task across five possible SOAs and both drug conditions. While both accuracy (a) and confidence (b) scaled with the duration of SOA, cabergoline had no effect on either of these measures
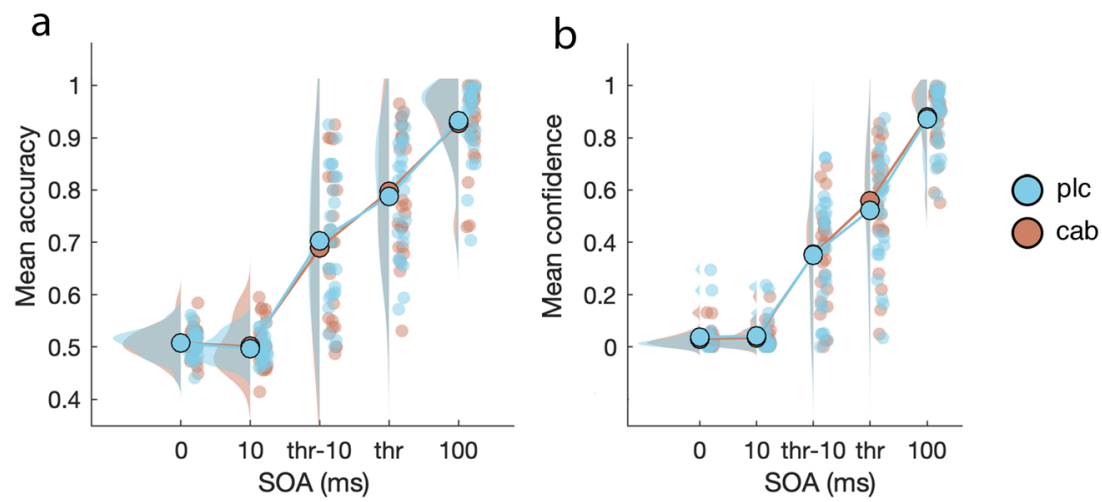

cabergoline would affect participant's ability to detect targets, there was no interaction between drug and $\mathrm{SOA}\left(\mathrm{F}_{(4,100)}<1\right.$, $p=.56 ; \mathrm{BF}_{\text {incl }}=.03$; see Fig. 7). We also did not find an overall difference between placebo and cabergoline on target identification accuracy $\left(\mathrm{F}_{(1,25)}<1, p=.85, \mathrm{BF}_{\text {incl }}=.13\right)$. Controlling for screening sEBR, OSPAN, or the combination of both did not change the results. Neither did the inclusion of a between-subject factor for drug order. We repeated these analyses with d' as the dependent variable, but results were equivalent.

Similarly, in the case of confidence scores, cabergoline did not affect reported confidence ratings, as indicated by the lack of an interaction between SOA and Drug $\left(\mathrm{F}_{(4,100)}=1.6\right.$, $p=.21 ; \mathrm{BF}_{\text {incl }}=.06$; see Fig. 7). We also found no overall difference between drug conditions $\left(\mathrm{F}_{(1,25)}<1, p=.63\right.$; $\left.\mathrm{BF}_{\text {incl }}=.14\right)$, but participants did report an improvement in response confidence as SOA increased $\left(\mathrm{F}_{(4,100)}=204.8\right.$, $\left.p<.001, \eta^{2}=.8 ; \mathrm{BF}_{\text {incl }}>100\right)$. Again, correcting for baseline dopamine measures or drug order had no impact on the results. As with d', repeating these analyses with meta-d' as the dependent variable made no difference. Thus, we replicated a similar pattern of results with regard to both objective and subjective aspects of the participant's response during backward masking (Del Cul et al. 2007), but these patterns were not affected by cabergoline.

EEG In addition to these behavioral masking effects, we replicated previous reports that target-evoked ERP components scale with the duration of target-mask SOA (Del Cul et al. 2007). We found a strong effect of SOA on the amplitude and peak latency of the target-evoked P1, N1, N2, and P3b components. However, in the case of our ERP results as well, each of these measures was unaffected by cabergoline (see Table 2 and Fig. 8). In order to remain close to previous studies (Del Cul et al. 2007), we repeated these analyses with an average reference instead of an earlobe reference, but the conclusions belonging to these results remained the same. Thus, cabergoline did not affect the threshold for conscious perception by modulating neural target processing.

\section{Attentional blink}

As expected and shown in Fig. 9, we found a robust attentional blink: T2|T1 accuracy was significantly worse when T2 was presented after one distractor (lag 2) compared to seven distractors $\left(\operatorname{lag} 8 ; \mathrm{F}_{(1,24)}=43.9, p<.001, \eta^{2}=.39 ; \mathrm{BF}_{\text {incl }}>\right.$ 100). T2|T1 accuracy was marginally better in the cabergoline condition $(81.9 \pm 11 \%)$ compared to placebo $\left(79.7 \pm 14 \% ; \mathrm{F}_{(1}\right.$, 24) $\left.=4.2, p=.052 ; \mathrm{BF}_{\text {incl }}=.34\right)$, but we found no interaction between lag and drug $\left(\mathrm{F}_{(1,24)}=1.42, p=.25 ; \mathrm{BF}_{\text {incl }}=.3\right)$.

When we controlled for baseline dopamine measures (i.e., baseline OSPAN and SEBR), the inclusion of OSPAN did not affect the results, and controlling for sEBR also did not reveal a critical interaction between lag and drug $\left(\mathrm{F}_{(1,22)}=1.3\right.$, $\left.p=.26 ; \mathrm{BF}_{\text {incl }}=.3\right)$. We did find a between-subject effect of screening $\operatorname{sEBR}\left(\mathrm{F}_{(1,22)}=5.2, p=.03 ; \mathrm{BF}_{\text {incl }}=2.5\right)$, which exacerbated the main effect of $\operatorname{drug}\left(\mathrm{F}_{(1,22)}=5.4, p=.029\right.$; $\left.\eta^{2}=.004 ; \mathrm{BF}_{\text {incl }}=.36\right)$. In addition, we found an interaction between $\operatorname{sEBR}$ and drug $\left(\mathrm{F}_{(1,22)}=5.8, p=.025 ; \eta^{2}=.005\right)$ : sEBR correlated with overall T2 $\mid \mathrm{T} 1$ accuracy in the placebo $\left(\tau_{(25)}=-.31, p=.03\right)$, but slightly less so in the cabergoline $\left(\tau_{(25)}=-.26, p=.07\right)$ condition.

Although the critical three-way interaction between sEBR, lag, and drug was not significant, we also found an interaction between screening sEBR and lag $\left(\mathrm{F}_{(1,22)}=5, p=.036\right.$; $\left.\eta^{2}=.004\right)$. This interaction is best understood in terms of the relationship between sEBR and $\mathrm{AB}$ size (Colzato et al. 2008; Slagter et al. 2012); namely, the difference in T2|T1 accuracy between lag 2 and 8 . AB size ranged from -2.9 to $59.7 \%$ in the placebo condition, and from $0 \%$ to $47.5 \%$ in the cabergoline condition. The interaction between sEBR and Lag stems from a small correlation between screening sEBR and $\mathrm{AB}$ size in the cabergoline $\left(\tau_{(25)}=.31, p=.03\right)$ and placebo condition $\left(\tau_{(25)}=.28, p=.047\right)$. We found no other relationships between dopamine baseline measures and the $\mathrm{AB}$; the difference in $\mathrm{AB}$ size between the cabergoline and placebo session was unrelated to screening $\operatorname{sEBR}\left(\tau_{(25)}=.05, p=.71\right)$. For the cabergoline session, there was no relation between $\mathrm{AB}$ size and $\operatorname{sEBR}\left(\tau_{(25)}=.13, p=.35\right)$, nor between $\mathrm{AB}$ size and 
Table 2 Summary of the statistical analyses performed on ERP data

\begin{tabular}{lllll}
\hline Component & Measure & $\operatorname{SOA}\left(\mathrm{F}_{(3,75)}=\right)$ & $\operatorname{Drug}\left(\mathrm{F}_{(1,25)}=\right)$ & $\operatorname{SOA}^{*}$ Drug $\left(\mathrm{F}_{(3,75)}=\right)$ \\
\hline $\mathrm{P} 1$ & Amplitude & $51.7, p<.001^{*}$ & $.01, p=.91, \mathrm{BF}_{\text {incl }}=.16$ & $.62, p=.60, \mathrm{BF}_{\text {incl }}=.08$ \\
& Latency & $8.2, p<.001^{*}$ & $.17, p=.68, \mathrm{BF}_{\text {incl }}=.16$ & $.48, p=.7, \mathrm{BF}_{\text {incl }}=.08$ \\
$\mathrm{~N} 1$ & Amplitude & $12.4, p<.001^{*}$ & $.04, p=.85, \mathrm{BF}_{\text {incl }}=.15$ & $.44, p=.73, \mathrm{BF}_{\text {incl }}=.06$ \\
& Latency & $66.8, p<.001^{*}$ & $.33, p=.57, \mathrm{BF}_{\text {incl }}=.19$ & $.07, p=.98, \mathrm{BF}_{\text {incl }}=.06$ \\
$\mathrm{~N} 2$ & Amplitude & $4.7, p=.005^{*}$ & $.04, p=.83, \mathrm{BF}_{\text {incl }}=.15$ & $.21, p=.89, \mathrm{BF}_{\text {incl }}=.06$ \\
& Latency & $99.3, p<.001^{*}$ & $2.9, p=.1, \mathrm{BF}_{\text {incl }}=.38$ & $.09, p=.97, \mathrm{BF}_{\text {incl }}=.06$ \\
P3b & Amplitude & $57.2, p<.001^{*}$ & $.02, p=.9, \mathrm{BF}_{\text {incl }}=.15$ & $.9, p=.44, \mathrm{BF}_{\text {incl }}=.07$ \\
& Latency & $10, p<.001^{*}$ & $.1, p=.74, \mathrm{BF}_{\text {incl }}=.15$ & $1.7, p=.18, \mathrm{BF}_{\text {incl }}=.09$ \\
\hline
\end{tabular}

${ }^{*}=$ BFincl $>100$
OSPAN $\left(\tau_{(25)}=.08, p=.57\right.$; see Fig. 10a). Similarly, for the placebo session, we did not find a relationship either between $\mathrm{AB}$ size and $\operatorname{sEBR}\left(\tau_{(25)}=.15, p=.3\right)$, nor OSPAN $\left(\tau_{(25)}=.02, p=.89\right.$, see Fig. $\left.10 \mathrm{~b}\right)$. However, none of the correlations reported in this section survived a Bonferroni correction for multiple comparisons using a corrected alpha level of $.05 / 9=.0056$, based on all correlations computed in this section. Thus, we found no strong support for a relationship between sEBR and the $\mathrm{AB}$, or OSPAN and the $\mathrm{AB}$, nor did controlling for these factors reveal drug-related effects on the $\mathrm{AB}$.

When controlling for drug order, we found an interaction between drug and drug order $\left(\mathrm{F}_{(1,21)}=5.7, p=.027\right.$; $\left.\eta^{2}=.004 ; \mathrm{BF}_{\text {incl }}=.43\right)$. When participants received placebo first, they were less accurate overall in identifying $\mathrm{T} 2 \mid \mathrm{T} 1$ in the placebo condition $(77.5 \pm 15 \%)$, compared to the cabergoline condition $(81.6 \pm 11 \%)$. For participants who received cabergoline first, this difference was not present (placebo: $82.1 \pm 12 \%$, cabergoline: $82.3 \pm 10 \%$ ). No other order effects were present. Together these results indicate that cabergoline did not affect the attentional blink.

We found no difference in $\mathrm{T} 1$ accuracy between the placebo and cabergoline condition $\left(\mathrm{F}_{(1,24)}<1, p=.49\right.$; $\left.\mathrm{BF}_{\text {incl }}=.27\right)$, or an interaction between drug and lag $\left(\mathrm{F}_{(1,24)}\right.$
$<1, p=.5 ; \mathrm{BF}_{\text {incl }}=.32$ ), but $\mathrm{T} 1$ accuracy was worse when $\mathrm{T} 2$ was presented after only one distractor (lag $2 ; \mathrm{F}_{(1,24)}=46.6$, $\left.p<.001, \eta^{2}=.16 ; \mathrm{BF}_{\text {incl }}>100\right)$. Controlling for sEBR, OSPAN, or drug order did not affect the results for T1 accuracy. Thus, cabergoline also did not affect $\mathrm{T} 1$ identification.

\section{Probabilistic discrimination}

In our final experimental paradigm, participants were tasked with discriminating between face and house stimuli that varied in difficulty and probability of occurrence (see "Methods"). Cabergoline did not affect discrimination accuracy (specifically: hit rate; $\left.\mathrm{F}_{(1,23)}=2.4, p=.13, \mathrm{BF}_{\text {incl }}=.35\right)$. Neither did we find an interaction between drug and difficulty $\left(\mathrm{F}_{(1,23)}<1\right.$, $\left.p=.91, \mathrm{BF}_{\text {incl }}=.14\right)$, drug and probability $\left(\mathrm{F}_{(4,92)}<1\right.$, $\left.p=.78, \mathrm{BF}_{\text {incl }}=.02\right)$, or a three-way interaction $\left(\mathrm{F}_{(4,92)}<1\right.$, $p=.48, \mathrm{BF}_{\text {incl }}=.05$; see Fig. 11a). Thus, cabergoline did not significantly affect perception on this task either. Standard effects observed with this task in non-drug studies were replicated (Bauer et al. 2016, September): accuracy was lower on difficult $\left(\mathrm{F}_{(1,23)}=208.3, p<.001, \eta^{2}=.60, \mathrm{BF}_{\text {incl }}>100\right)$ and on low-probability trials $\left(\mathrm{F}_{(4,92)}=22.49, p<.001, \eta^{2}=.04\right.$, $\left.\mathrm{BF}_{\text {incl }}>100\right)$. When we controlled for screening sEBR and OSPAN, this did not change the results. We did find an
Fig. 8 Effects of cabergoline on target-evoked ERPs in the backward masking task. This figure displays the grand-average targetevoked ERPs for P3b electrodes (P1, Pz, P2, PO3, POz, PO4) for both drug conditions combined (a) and separately (b), per targetmask SOA condition $(10,40,50$, 60,70 , and $100 \mathrm{~ms}$ ). This figure shows that while ERP amplitudes and latencies generally increased as a function of target-mask SOA, these measures were unaffected by cabergoline
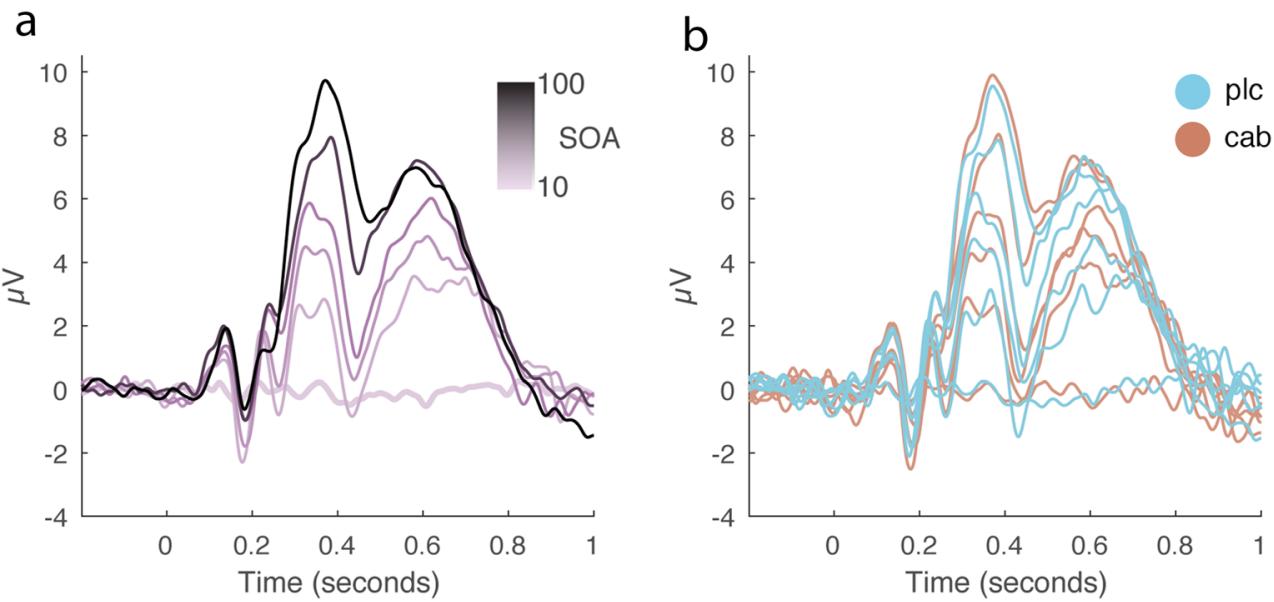
Fig. 9 Mean accuracy for T1 and $\mathrm{T} 2 \mid \mathrm{T} 1$ at lag 2 and lag 8 . While we replicated behavioral findings common to the attentional blink paradigm, cabergoline did not affect the attentional blink
T1

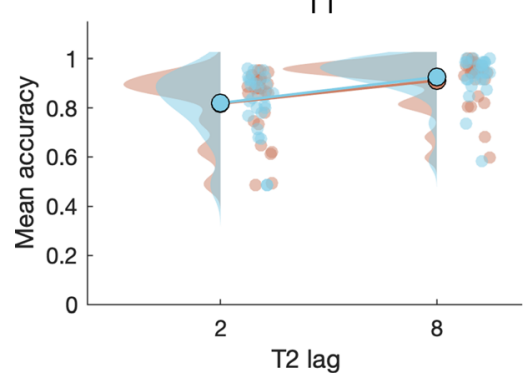

$\mathrm{T} 2$ | $\mathrm{T} 1$

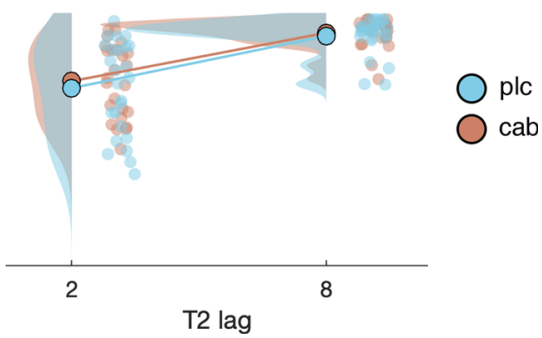

interaction between drug order and $\operatorname{drug}\left(\mathrm{F}_{(4,88)}=5.2, p=.03\right.$, $\mathrm{BF}_{\text {incl }}=1.3$ ). Opposite to what we found for the attentional blink task, when participants received placebo first, they were more accurate overall in the placebo $(84 \pm 7 \%)$ compared to the cabergoline $(82.4 \pm 7 \%)$ condition. When cabergoline was administered first, this difference was absent (placebo: $83.5 \pm$ $5 \%$, cabergoline: $83.1 \pm 4 \%$ ). We found no other order effects.

When we repeated these analyses for participants with all three difficulty levels for both stimuli after titration $(N=16$; see "Methods"), the same pattern of results was obtained. Cabergoline did not affect discrimination accuracy $\left(\mathrm{F}_{(1,15)}<\right.$ $\left.1, p=.47, \mathrm{BF}_{\text {incl }}=.69\right)$, and we found no two-way interaction between drug and difficulty $\left(\mathrm{F}_{(2,30)}<1, p=.59, \mathrm{BF}_{\text {incl }}=.05\right)$, drug and probability $\left(\mathrm{F}_{(4,60)}<1, p=.76, \mathrm{BF}_{\text {incl }}=.02\right)$, or a three-way interaction $\left(\mathrm{F}_{(8,120)}=1.1, p=.4, \mathrm{BF}_{\text {incl }}=.04\right.$; see Fig. 11b). Accuracy was still lower on difficult $\left(\mathrm{F}_{(2,30)}=\right.$ 233.8, $\left.p<.001, \eta^{2}=.53, \mathrm{BF}_{\mathrm{incl}}>100\right)$ and low-probability trials $\left(\mathrm{F}_{(4,60)}=21.1, p<.001, \eta^{2}=.08, \mathrm{BF}_{\text {incl }}>100\right)$. Controlling for screening sEBR and OSPAN did not change the acquired results. The interaction between drug order and drug was maintained $\left(\mathrm{F}_{(1,14)}=9.9, p=.007, \mathrm{BF}_{\text {incl }}>100\right)$, where overall accuracy was higher in the placebo condition $(83 \pm 7 \%)$ when placebo was administered first compared to the cabergoline condition $(80.6 \pm 6 \%)$. This difference was again absent when cabergoline was administered first (placebo $82.7 \pm 3 \%$, cabergoline $83.1 \pm 3 \%$ ).

Thus, we found no evidence in support of the conclusion that cabergoline affected any of the key findings in our perceptual tasks.

\section{Discussion}

This double-blind, placebo-controlled, crossover study tested the hypothesis that striatal dopamine is involved in conscious perception by administering the dopamine D2 agonist cabergoline and placebo to healthy participants. To that end, (1) we established an effect of cabergoline on participant's a
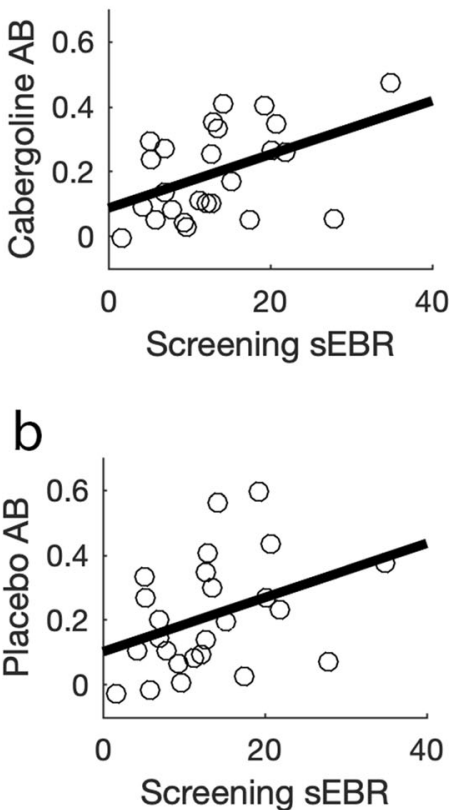
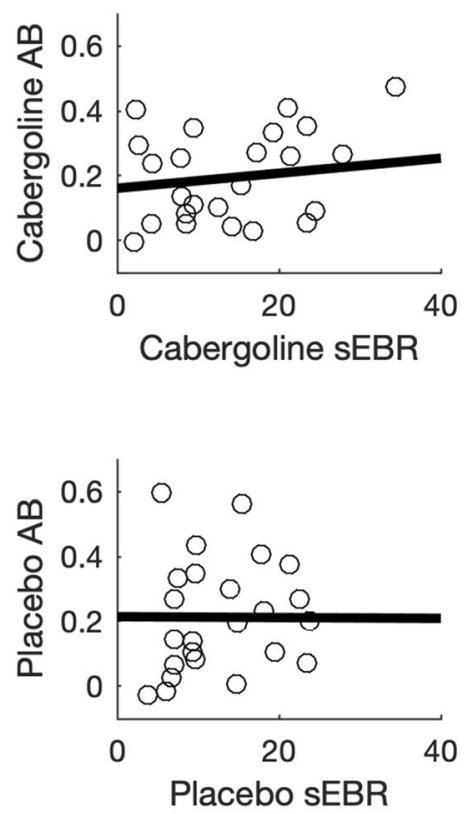
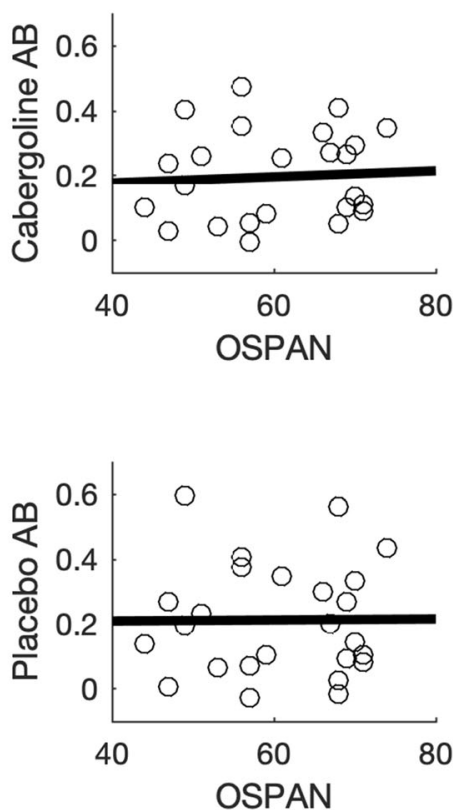

Fig. 10 The relationship between $\mathrm{AB}$ size and striatal dopamine proxy measures. Both for the cabergoline and placebo condition, we found a positive relation between $\mathrm{AB}$ size and screening sEBR, while such a relationship was not present neither for sEBR measured within the same session, nor for OSPAN 
Fig. 11 Cabergoline did not affect probabilistic discrimination performance. This figure shows mean accuracy for each drug condition and across five stimulus probabilities for all participants with two $(\mathbf{a} ; N=24)$ and three $(\mathbf{b}$; $\mathrm{N}=16$ ) difficulty levels after titration. While accuracy was higher for easy trials and blocks in which the presented stimulus was more likely to occur, these effects were unaffected by cabergoline. Medium-difficulty trials take up position in between easy and hard trials in terms of mean accuracy when included
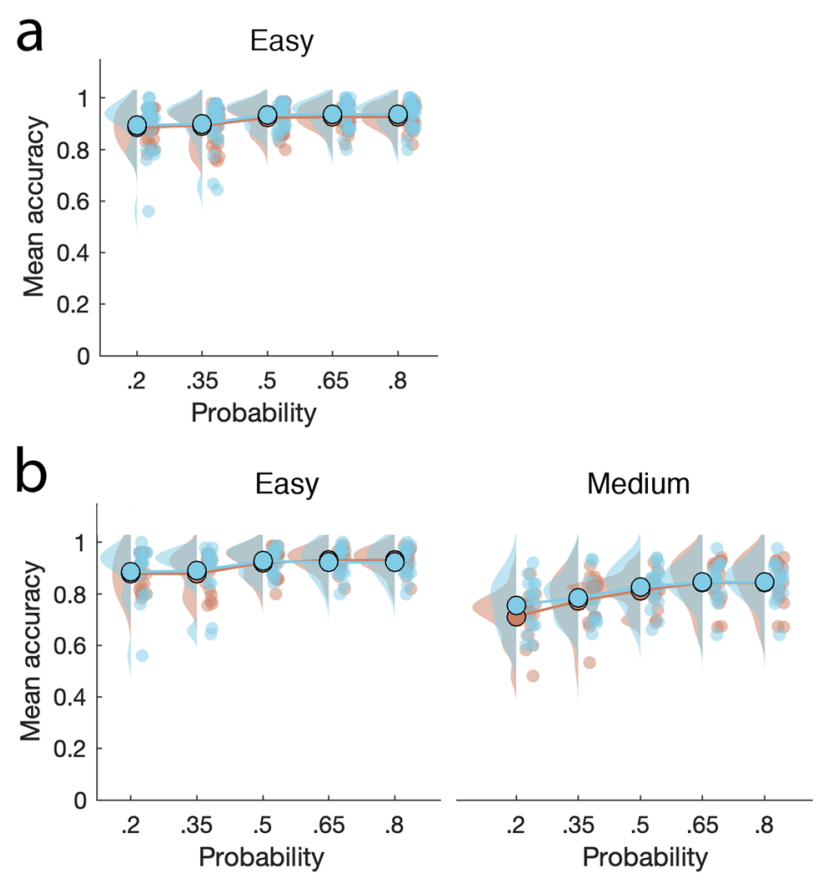

Hard

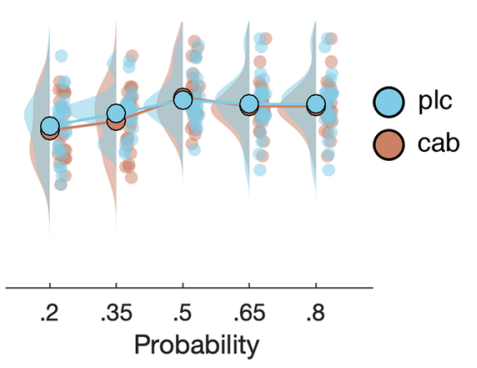

Hard

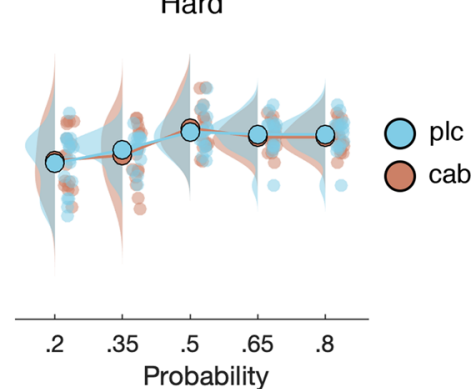

physiological and subjective state, (2) we tested the effect of cabergoline on two often-used dopamine proxy measures (sEBR and OSPAN), and (3) we subjected participants to well-known and often-employed experimental paradigms targeting the neural correlates of consciousness. While we were able to establish an effect of cabergoline on participant's physiological and subjective state, we did not find an effect of cabergoline on SEBR. Crucially, while we replicated key behavioral and ERP findings associated with the paradigms we employed (Del Cul et al. 2007; Slagter et al. 2017; Van Opstal et al. 2014), none of these findings were affected by cabergoline. Thus, we did not obtain evidence that the dopamine D2 agonist cabergoline affected conscious perception, which was also supported by Bayesian statistics.

Just as with positive results, an observed null result could indicate a true effect (i.e., no role for striatal dopamine in conscious perception), or it could be due to uncontrolled or unknown factors. Based on the convergent evidence discussed in the introduction implicating the striatum and its irrigation by dopamine in conscious perception (e.g., Bisenius et al., 2015; Slagter et al. 2017; Van Opstal et al. 2014), we predicted that cabergoline would affect performance on the backward masking and attentional blink tasks. Yet, our Bayesian results provided evidence against an effect of $1.5 \mathrm{mg}$ cabergoline (all $\mathrm{BF}_{\text {incl }}<.7$; except for the interaction between drug and drug order for discrimination accuracy in the probabilistic discrimination task). This absence of an effect is further strengthened by the fact that other studies using different cognitive tasks have previously reported significant effects of cabergoline on task performance using a similar or an even lower dose of orally administered cabergoline (Broadway et al. 2018;
Cavanagh et al. 2014; Fallon et al. 2017; Frank \& O'Reilly, 2006; Norbury et al. 2013; Nandam et al. 2013; Yousif et al., 2016). These observations together argue for an interpretation in terms of a true null result. Nonetheless, there are a number of practical limitations that pertain to the present study.

For one, blinding was unsuccessful as $85 \%$ of participants guessed when they received cabergoline at the end of the experiment. While all participants with adverse reactions were excluded from any analyses, we cannot exclude the possibility that participants' ability to tell when they received cabergoline influenced the results. It is possible this ability stems from the higher dosage $(1.5 \mathrm{mg})$ we employed compared to previous studies administering cabergoline (1-1.25 mg; Broadway et al. 2018; Cavanagh et al. 2014; Frank and O'Reilly 2006; Norbury et al. 2013; Nandam et al. 2013; Yousif et al. 2016). While a lower dosage may benefit blinding, it may also further reduce the chance of finding an effect of cabergoline. Another option for future research would be to administer an antiemetic such as domperidone in combination with cabergoline, in order to mitigate and mask physical side effects (Fallon et al., 2017; Norbury et al. 2013).

Second, while we titrated performance on the backward masking and probabilistic discrimination tasks, we did not do so for the attentional blink task, which may have resulted in reduced sensitivity of this task to our dopamine manipulation. We chose this specific version of the task in order to stay as close as possible to a recent study in which we found a relationship between activity in the ventral striatum and the attentional blink (Slagter et al. 2017). While we cannot rule out that a titration procedure may have resulted in a task more 
sensitive to our manipulation, we believe this is unlikely given that our participants showed a robust attentional blink, indicating that our task was suitable for the effect we intended to manipulate. In addition, since cabergoline did not affect performance on the two tasks we did titrate, we believe it unlikely that this would have been different in the case of the attentional blink task.

Third, a limitation of our study pertains to the use of alleged indirect measures of dopamine activity: sEBR (Jongkees and Colzato 2016) and the OSPAN task (Cools et al. 2008). The functioning of dopamine relies on a relative equilibrium at the system level (i.e., frontal versus basal ganglia; Wiecki \& Frank, 2013; Wise et al. 1996), within the basal ganglia itself (i.e., direct versus indirect pathways; Redgrave et al. 2010), and at the level of synapses (i.e., pre- versus postsynaptic effects; Frank and O'Reilly 2006; Usiello et al. 2000). The equilibrium at the system- and pathway-level is in turn implicated in the differing effects at the receptor level (i.e., D1 versus D2 receptors) (Shen et al. 2008). Due to the complexity and the multitude of interactions between different systems, it is especially important to be able to report on the initial state of the dopamine system.

Unfortunately, sEBR was unaffected by cabergoline. While this finding goes against studies with humans showing effects of dopaminergic drugs on sEBR (Blin et al. 1990; Karson, 1983; Strakowski and Sax 1998), this finding fits with several pharmacological studies that reported no effect (Depue et al. 1994; Ebert, 1996; Mohr et al. 2005; van der Post et al. 2004).

Moreover, differences in OSPAN and SEBR were unpredictive for the effect of cabergoline on performance in our experimental paradigms. These findings are surprising in light of previous work showing how effects of cabergoline on cognitive function depend on individual baseline sEBR (Cavanagh et al. 2014) and OSPAN score (Broadway et al., 2018). However, it should be emphasized that evidence for a relationship between dopamine proxy measures and dopamine levels is often correlational, based on studies with small sample sizes $(N<50$; Cools et al. 2008), and that results are mixed (Dang et al. 2017; Sescousse et al. 2018). It is debatable whether such small-sample studies have adequate power to provide evidence for this relationship (Cremers et al. 2017; Rousselet and Pernet, 2012). Similarly, the correlational findings we report should also be interpreted cautiously. While measures such as OSPAN and sEBR are easy to administer, the correlational evidence - as well as inconsistent findings regarding these measures (Dang et al. 2017; Jongkees and Colzato 2016; Sescousse et al. 2018) - put pressure on their validity as an index of baseline dopamine levels.

Despite these practical limitations, the advantage of our study is that our results are univocal: the administration of cabergoline had no effect on any of our indices of conscious perception obtained using often-employed experimental paradigms in the study of consciousness. Of importance, we did consistently replicate all key behavioral and event-related potential (ERP) findings associated with each of these tasks.

Theoretically, perhaps our null findings are best explained by an appeal to predictive processing approaches to brain function (Hohwy, 2012, 2013; de Lange et al. 2018). From the perspective of these theories, the brain is viewed as a prediction machine which is continuously revising its predictions about the causes of sensory data. On this view, top-down signals in perceptual hierarchies carry perceptual predictions, while bottom-up signals convey perceptual prediction errors. Perception becomes a process of continual minimization of prediction errors across hierarchical levels, instantiating a process of approximate Bayesian inference on the causes of sensory signals. In this process, dopamine is thought to regulate the relative precision of top-down predictions and bottom-up prediction errors, where precision is understood as inverse variance (Friston et al. 2012): a higher (expected) variance of sensory signals leads to a smaller influence on updating perceptual predictions. "If true, this means that modulators of synaptic gain (like dopamine) do not report perceptual content but the context in which percepts are formed. In other words, dopamine reports the precision or salience of sensorimotor constructs (representations) encoded by the activity of the synapses they modulate." (Friston et al. 2012, p. 2).

From this perspective, there may not have been enough uncertainty in our experimental paradigms for our dopamine manipulation to play a determining role. Indeed, previous studies employing cabergoline in the context of working memory found an effect under conditions where taskrelevant targets were embedded in a larger perceptual field; namely, in the presence of distractors. In these studies, cabergoline exerted an effect on task performance in terms of target-detection accuracy and successful recall when a target stood in competition with other stimuli (Broadway et al., 2018; Cavanagh et al. 2014; Frank and O'Reilly, 2006). In the case of each of our tasks, targets were consistently surrounded by distracting information temporally, but never spatially. Perhaps the selective functionalities of the basal ganglia and dopaminergic firing actualize primarily when the system is under pressure to select sensorimotor constructs in the face of multidimensional uncertainty.

Our data cast doubt on a causal role for dopamine in visual perception, as shown by a significant lack of effect in several standard perceptual paradigms. Future studies, perhaps with more direct measures of dopaminergic activity, and more naturalistic paradigms including more opportunities for selection and/ or uncertainty, may yet reveal a more specific influence of this neurotransmitter on how we perceptually encounter the world.

Funding information This work was supported by an ERC starting grant to HAS by the H2020 European Research Council [ERC-2015-STG679399] and an Amsterdam Brain and Cognition (ABC) grant to HAS, AKS, and CSL. AKS is additionally grateful to the Canadian Institute for Advanced Research (CIFAR) Azrieli Programme on Brain, Mind, and Consciousness, and to the Dr. Mortimer and Theresa Sackler Foundation. 
Data availability Datasets and code are available from the corresponding author on request.

\section{Compliance with ethical standards}

Conflict of interest The authors declare that they have no competing interests.

Open Access This article is licensed under a Creative Commons Attribution 4.0 International License, which permits use, sharing, adaptation, distribution and reproduction in any medium or format, as long as you give appropriate credit to the original author(s) and the source, provide a link to the Creative Commons licence, and indicate if changes were made. The images or other third party material in this article are included in the article's Creative Commons licence, unless indicated otherwise in a credit line to the material. If material is not included in the article's Creative Commons licence and your intended use is not permitted by statutory regulation or exceeds the permitted use, you will need to obtain permission directly from the copyright holder. To view a copy of this licence, visit http://creativecommons.org/licenses/by/4.0/.

\section{References}

Agúndez JA, Garcia-Martin E, Alonso-Navarro H, Jiménez-Jiménez FJ (2013) Anti-Parkinson's disease drugs and pharmacogenetic considerations. Expert Opin Drug Metab Toxicol 9(7):859-874

Alexander GE, DeLong MR, Strick PL (1986) Parallel organization of functionally segregated circuits linking basal ganglia and cortex. Annu Rev Neurosci 9(1):357-381

Alexander GE, Crutcher MD (1990) Functional architecture of basal ganglia circuits: neural substrates of parallel processing. Trends Neurosci 13(7): 266-271. https://doi.org/10.1016/0166-2236(90)90107-L

Allen M, Poggiali D, Whitaker K, Marshall TR, Kievit RA (2019) Raincloud plots: a multi-platform tool for robust data visualization. Wellcome Open Research 4(63). https://doi.org/10.12688/ wellcomeopenres.15191.1

Arsalidou M, Duerden EG, Taylor MJ (2013) The centre of the brain: topographical model of motor, cognitive, affective, and somatosensory functions of the basal ganglia. Hum Brain Mapp 34(11):30313054. https://doi.org/10.1002/hbm.22124

Barbato G, Ficca G, Muscettola G, Fichele M, Beatrice M, Rinaldi F (2000) Diurnal variation in spontaneous eye-blink rate. Psychiatry Research 93(2):145-151

Bauer M, Wislowska M, Veale T, Morris PG, Liddle PF, Heekeren HR, Brookes MJ (2016) Brain rhythms shape Bayesian integration of prior predictions with precision weighted sensory information for perceptual decisions. Annual meeting of the Society for Neuroscience. San Diego, CA

Berke JD (2018) What does dopamine mean? Nat Neurosci:1-1. https:// doi.org/10.1038/s41593-018-0152-y

Bisenius S, Trapp S, Neumann J, Schroeter ML (2015) Identifying neural correlates of visual consciousness with ALE meta-analyses. NeuroImage 122:177-187. https://doi.org/10.1016/j.neuroimage. 2015.07.070

Blin O, Masson G, Azulay J, Fondarai J, Serratrice G (1990) Apomorphine-induced blinking and yawning in healthy volunteers. Br J Clin Pharmacol 30(5):769-773. https://doi.org/10.1111/j.13652125.1990.tb03848.x

Boly M, Massimini M, Tsuchiya N, Postle BR, Koch C, Tononi G (2017) Are the neural correlates of consciousness in the front or in the back of the cerebral cortex? Clinical and neuroimaging evidence. J
Neurosci 37(40):9603-9613. https://doi.org/10.1523/JNEUROSCI. 3218-16.2017

Bond A, and Lader M (1974) The use of analogue scales in rating subjective feelings. British Journal of Medical Psychology, 47(3), 211-218. https://doi.org/10.1111/j.2044-8341.1974.tb02285.x

Bonett DG, Wright TA (2000) Sample size requirements for estimating Pearson, Kendall and Spearman correlations. Psychometrika 65(1): 23-28. https://doi.org/10.1007/BF02294183

Brainard DH (1997) The psychophysics toolbox. Spat Vis 10(4):433436. https://doi.org/10.1163/156856897X00357

Breitmeyer B (2007) Visual masking: past accomplishments, present status, future developments. Adv Cogn Psychol 3(1-2):9-20. https:// doi.org/10.2478/v10053-008-0010-7

Broadway JM, Frank MJ, Cavanagh JF (2018) Dopamine D2 agonist affects visuospatial working memory distractor interference depending on individual differences in baseline working memory span. Cognitive, Affective, \& Behavioral Neuroscience 18(3):509-520. https://doi.org/10.3758/s13415-018-0584-6

Brown LL, Schneider JS, Lidsky TI (1997) Sensory and cognitive functions of the basal ganglia. Curr Opin Neurobiol 7(2):157-163. https://doi.org/10.1016/S0959-4388(97)80003-7

Brown SBRE, Slagter HA, van Noorden MS, Giltay EJ, van der Wee NJA, Nieuwenhuis S (2016) Effects of clonidine and scopolamine on multiple target detection in rapid serial visual presentation. Psychopharmacology 233(2):341-350. https://doi.org/10.1007/ s00213-015-4111-y

Cassidy CM, Balsam PD, Weinstein JJ, Rosengard RJ, Slifstein M, Daw ND et al (2018) A perceptual inference mechanism for hallucinations linked to striatal dopamine. Current Biology, 28(4), 503514.e4. https://doi.org/10.1016/j.cub.2017.12.059

Cavanagh JF, Masters SE, Bath K, Frank MJ (2014) Conflict acts as an implicit cost in reinforcement learning. Nat Commun 5:5394-5394. https://doi.org/10.1038/ncomms6394

Cohen MX, Krohn-Grimberghe A, Elger CE, Weber B (2007) Dopamine gene predicts the brain's response to dopaminergic drug. European Journal of Neuroscience 26(12):3652-3660

Colzato LS, Slagter HA, Spapé MMA, Hommel B (2008) Blinks of the eye predict blinks of the mind. Neuropsychologia 46(13):31793183. https://doi.org/10.1016/j.neuropsychologia.2008.07.006

Cools R, Gibbs SE, Miyakawa A, Jagust W, D’Esposito M (2008) Working memory capacity predicts dopamine synthesis capacity in the human striatum. J Neurosci 28(5):1208-1212. https://doi.org/10. 1523/JNEUROSCI.4475-07.2008

Cools R, D'Esposito M (2011) Inverted-U-shaped dopamine actions on human working memory and cognitive control. Biol Psychiatry 69(12):e113-e125. https://doi.org/10.1016/j.biopsych.2011.03.028

Cools R (2011) Dopaminergic control of the striatum for high-level cognition. Current Opinion in Neurobiology 21(3):402-407. https://doi. org/10.1016/j.conb.2011.04.002

Cox J, Witten IB (2019) Striatal circuits for reward learning and decisionmaking. Nat Rev Neurosci 20:482-494. https://doi.org/10.1038/ s41583-019-0189-2

Cremers HR, Wager TD, Yarkoni T (2017) The relation between statistical power and inference in fMRI. PLoS One 12(11):e0184923. https://doi.org/10.1371/journal.pone.0184923

Crick F, Koch C (2003) A framework for consciousness. Nat Neurosci 6(2):119-126. https://doi.org/10.1038/nn0203-119

Czoty PW, Riddick NV, Gage HD, Sandridge M, Nader SH, Garg S, Bounds M, Garg PK, Nader MA (2009) Effect of menstrual cycle phase on dopamine D2 receptor availability in female cynomolgus monkeys. Neuropsychopharmacology 34(3):548-554. https://doi. org/10.1038/npp.2008.3

Dakin SC, Hess RF, Ledgeway T, Achtman RL (2002) What causes nonmonotonic tuning of fMRI response to noisy images? Curr Biol 12(14): R476-R477. https://doi.org/10.1016/S0960-9822(02)00960-0 
Dang, L. C., Samanez-Larkin, G. R., Castrellon, J. J., Perkins, S. F., Cowan, R. L., Newhouse, P. A., \& Zald, D. H. (2017). Spontaneous eye blink rate (EBR) is uncorrelated with dopamine D2 receptor availability and Unmodulated by dopamine agonism in healthy adults. Eneuro, 4(5), ENEURO.0211-17.2017. https://doi. org/10.1523/ENEURO.0211-17.2017

Dehaene S, Changeux J-P (2011) Experimental and theoretical approaches to conscious processing. Neuron 70(2):200-227. https:// doi.org/10.1016/j.neuron.2011.03.018

Del Cul A, Baillet S, Dehaene S (2007) Brain dynamics underlying the nonlinear threshold for access to consciousness. PLoS Biol 5(10): 2408-2423. https://doi.org/10.1371/journal.pbio.0050260

Del Cul A, Dehaene S, Leboyer M (2006) Preserved subliminal processing and impaired conscious access in schizophrenia. Arch Gen Psychiatry 63(12):1313-1323. https://doi.org/10.1001/archpsyc.63.12.1313

Delorme A, Makeig S (2004) EEGLAB: an open source toolbox for analysis of single-trial EEG dynamics including independent component analysis. J Neurosci Methods 134(1):9-21. https://doi.org/ 10.1016/j.jneumeth.2003.10.009

Depue RA, Luciana M, Arbisi P, Collins P, Leon A (1994) Dopamine and the structure of personality: relation of agonist-induced dopamine activity to positive emotionality. J Pers Soc Psychol 67(3):485-498. https://doi.org/10.1037/0022-3514.67.3.485

Ding L, Gold J (2013) The basal ganglia's contributions to perceptual decision making. Neuron 79(4):640-649. https://doi.org/10.1016/j. neuron.2013.07.042

Ebert D (1996) Eye-blink rates and depression is the antidepressant effect of sleep deprivation mediated by the dopamine system? Neuropsychopharmacology 15(4):332-339. https://doi.org/10. 1016/0893-133X(95)00237-8

Edelman GM (2003) Naturalizing consciousness: a theoretical framework. Proc Natl Acad Sci 100(9):5520-5524. https://doi.org/10. 1073/pnas.0931349100

Fallon SJ, Zokaei N, Norbury A, Manohar SG, Husain M (2017) Dopamine alters the fidelity of working memory representations according to attentional demands. J Cogn Neurosci 29(4):728738. https://doi.org/10.1162/jocn_a_ 01073

Ford CP (2014) The role of D2-autoreceptors in regulating dopamine neuron activity and transmission. Neuroscience 282:13-22. https:// doi.org/10.1016/j.neuroscience.2014.01.025

Frank MJ, Loughry B, O'Reilly RC (2001) Interactions between frontal cortex and basal ganglia in working memory: a computational model. Cognitive, Affective, \& Behavioral Neuroscience 1(2):137-160. https://doi.org/10.3758/CABN.1.2.137

Frank MJ, O'Reilly RC (2006) A mechanistic account of striatal dopamine function in human cognition: psychopharmacological studies with cabergoline and haloperidol. Behav Neurosci 120(3):497-517. https://doi.org/10.1037/0735-7044.120.3.497

Fridman EA, Osborne JR, Mozley PD, Victor JD, Schiff ND (2019) Presynaptic dopamine deficit in minimally conscious state patients following traumatic brain injury. Brain. 142:1887-1893. https://doi. org/10.1093/brain/awz118

Friston KJ, Shiner T, FitzGerald T, Galea JM, Adams R, Brown H, Dolan RJ, Moran R, Stephan KE, Bestmann S (2012) Dopamine, affordance and active inference. PLoS Comput Biol 8(1): e1002327. https://doi.org/10.1371/journal.pcbi.1002327

Gerfen CR (1992) The neostriatal mosaic: multiple levels of compartmental organization, In Advances in Neuroscience and Schizophrenia (pp. 43-59). Springer, Vienna

Gramfort A, Luessi M, Larson E, Engemann DA, Strohmeier D, Brodbeck C et al (2013) MEG and EEG data analysis with MNEPython. Front Neurosci 7:267-267. https://doi.org/10.3389/fnins. 2013.00267

Green DM, Swets JA (1966) Signal detection theory and psychophysics. New York: Wiley
Haber SN, Kim KS, Mailly P, \& Calzavara, R. (2006). Reward-related cortical inputs define a large striatal region in primates that interface with associative cortical connections, providing a substrate for incentive-based learning. Journal of Neuroscience, 26(32), 8368 8376.

Heilbronner SR, Meyer MA, Choi EY, \& Haber SN (2018) How do cortico-striatal projections impact on downstream pallidal circuitry? Brain Structure and Function, 223(6), 2809-2821.

Hohwy J (2012) Attention and conscious perception in the hypothesis testing brain. Front Psychol 3:96

Hohwy J (2013) The predictive mind. Oxford University Press

Hutton JT, Morris JL, Elias JW (1999) Visual contrast sensitivity in Parkinson's disease is worsened with cabergoline treatment. Parkinsonism and Related Disorders 5(3):87-91. https://doi.org/ 10.1016/S1353-8020(99)00021-8

JASP Team (2019). JASP (Version 0.10.0)[Computer software]

Jongkees BJ, Colzato LS (2016) Spontaneous eye blink rate as predictor of dopamine-related cognitive function-a review. Neurosci Biobehav Rev 71:58-82. https://doi.org/10.1016/j.neubiorev.2016. 08.020

Karson CN (1983) Spontaneous eye-blink rates and dopaminergic systems. Brain 106(3):643-653. https://doi.org/10.1093/brain/106.3.643

Kruis A, Slagter HA, Bachhuber DR, Davidson RJ, \& Lutz A. (2016). Effects of meditation practice on spontaneous eyeblink rate. Psychophysiology, 53(5), 749-758.

de Lange FP, Heilbron M, Kok P (2018) How do expectations shape perception? Trends Cogn Sci 22(9):764-779

Lou H, Skewes J, Thomsen K, Overgaard M, Lau H, Mouridsen K, Roepstorff A (2011) Lou et al. 2011. Dopaminergic stimulation enhances confidence and accuracy in seeing rapidly presented words.pdf. J Vis 11(2):1-6. https://doi.org/10.1167/11.2.15. Introduction

Mailly, P., Aliane, V., Groenewegen, H. J., Haber, S. N., \& Deniau, J. M. (2013). The rat prefrontostriatal system analyzed in 3D: evidence for multiple interacting functional units. Journal of Neuroscience, 33(13), 5718-5727.

Maniscalco B, Lau H (2012) A signal detection theoretic approach for estimating metacognitive sensitivity from confidence ratings. Consciousness and Cognition 21(1):422-430

Minear M, Park DC (2004) A lifespan database of adult facial stimuli. Behav Res Methods Instrum Comput 36(4):630-633. https://doi. org/10.3758/BF03206543

Mohr C, Sándor PS, Landis T, Fathi M, Brugger P (2005) Blinking and schizotypal thinking. J Psychopharmacol 19(5):513-520. https:// doi.org/10.1177/0269881105056538

Nandam LS, Hester R, Wagner J, Dean AJ, Messer C, Honeysett A, Nathan PJ, Bellgrove MA (2013) Dopamine D 2 receptor modulation of human response inhibition and error awareness. J Cogn Neurosci 25(4):649-656. https://doi.org/10.1162/jocn a 00327

Norbury A, Manohar S, Rogers RD, Husain M (2013) Dopamine modulates risk- taking as a function of baseline sensation-seeking trait. Journal of Neuroscience 33(32):12982-12986

Oostenveld R, Fries P, Maris E, Schoffelen J-M (2011) FieldTrip: open source software for advanced analysis of MEG, EEG, and invasive electrophysiological data. Computational Intelligence and Neuroscience 2011:1-9. https://doi.org/10.1155/2011/156869

Palmiter RD (2011) Dopamine signaling as a neural correlate of consciousness. Neuroscience 198:213-220. https://doi.org/10.1016/j. neuroscience.2011.06.089

Persiani S, Rocchetti M, Pacciarini MA, Holt B, Toon S, StrolinBenedetti M (1996) The effect of food on cabergoline pharmacokinetics and tolerability in healthy volunteers. Biopharm Drug Dispos 17(5):443-455

Redgrave P, Prescott TJ, Gurney K (1999) The basal ganglia: a vertebrate solution to the selection problem? Neuroscience 89(4):1009-1023. https://doi.org/10.1016/S0306-4522(98)00319-4 
Redgrave P, Rodriguez M, Smith Y, Rodriguez-Oroz MC, Lehericy S, Bergman H, Agid Y, DeLong MR, Obeso JA (2010) Goal-directed and habitual control in the basal ganglia: implications for Parkinson's disease. Nat Rev Neurosci 11(11):760-772. https:// doi.org/10.1038/nrn2915

Rousselet GA, Pernet CR (2012) Improving standards in brain-behavior correlation analyses. Front Hum Neurosci 6. https://doi.org/10. 3389/fnhum.2012.00119

Schultz W (2016) Dopamine reward prediction-error signalling: a twocomponent response. Nat Rev Neurosci 17(3):183-195. https://doi. org/10.1038/nrn.2015.26

Seger CA (2008) How do the basal ganglia contribute to categorization? Their roles in generalization, response selection, and learning via feedback. Neurosci Biobehav Rev 32(2):265-278. https://doi.org/ 10.1016/j.neubiorev.2007.07.010

Seger CA (2013) The visual corticostriatal loop through the tail of the caudate: circuitry and function. Front Syst Neurosci 7(104). https:// doi.org/10.3389/fnsys.2013.00104

Sescousse G, Ligneul R, van Holst RJ, Janssen LK, de Boer F, Janssen M, Berry AS, Jagust WJ, Cools R (2018) Spontaneous eye blink rate and dopamine synthesis capacity: preliminary evidence for an absence of positive correlation. Eur J Neurosci 47(9):1081-1086. https://doi.org/10.1111/ejn.13895

Shapiro KL, Raymond JE, Arnell KM (1997) The attentional blink. Trends Cogn Sci 1(8):291-296. https://doi.org/10.1016/S13646613(97)01094-2

Sheehan DV, Lecrubier Y, Sheehan KH, Amorim P, Janavs J, Weiller E, Hergueta T, Baker R, \& Dunbar GC (1998). The Mini-International Neuropsychiatric Interview (M.I.N.I): The development and validation of a structured diagnostic psychiatric interview for DSM-IV and ICD-10. The Journal of Clinical Psychiatry, 59(Suppl 20), 22-33.

Shen W, Flajolet M, Greengard P, Surmeier DJ (2008) Dichotomous dopaminergic control of striatal synaptic plasticity. Science (New York, N.Y.), 321(5890), 848-851. https://doi.org/10.1126/science. 1160575

Slagter HA, Mazaheri A, Reteig LC, Smolders R, Figee M, Mantione M, Schuurman PR, Denys D (2017) Contributions of the ventral striatum to conscious perception: an intracranial EEG study of the attentional blink. J Neurosci 37(5):1081-1089. https://oi.org/10.1523/ JNEUROSCI.2282-16.2016

Slagter HA, Tomer R, Christian BT, Fox AS, Colzato LS, King CR, Murali D, Davidson RJ (2012) PET evidence for a role for striatal dopamine in the attentional blink: functional implications. J Cogn Neurosci 24(9):1932-1940. https://doi.org/10.1162/jocn_a_00255

Smith Y, Raju DV, Pare J-F, Sidibe M (2004) The thalamostriatal system: a highly specific network of the basal ganglia circuitry. Trends Neurosci 27(9):520-527. https://doi.org/10.1016/j.tins.2004.07.004
Strakowski SM, Sax KW (1998) Progressive behavioral response to repeated d-amphetamine challenge: further evidence for sensitization in humans. Biol Psychiatry 44(11):1171-1177. https://doi.org/10. 1016/S0006-3223(97)00454-X

Taylor JR, Elsworth JD, Lawrence MS, Sladek JR, Roth RH, Redmond DE (1999) Spontaneous blink rates correlate with dopamine levels in the caudate nucleus of MPTP-treated monkeys. Exp Neurol 158(1):214-220. https://doi.org/10.1006/exnr.1999.7093

Unsworth N, Heitz RP, Schrock JC, Engle RW (2005) An automated version of the operation span task. Behav Res Methods 37(3):498505. https://doi.org/10.3758/BF03192720

Usiello A, Baik JH, Rougé-Pont F, Picetti R, Dierich A, LeMeur M, Piazza PV, Borrelli E (2000) Distinct functions of the two isoforms of dopamine D2 receptors. Nature 408(6809):199-203. https://doi. org/10.1038/35041572

Van Breukelen GJP, Van Dijk KRA (2007) Use of covariates in randomized controlled trials. J Int Neuropsychol Soc 13(05). https://doi.org/ 10.1017/S1355617707071147

van der Post J, de Waal PP, de Kam ML, Cohen AF, van Gerven JMA (2004) No evidence of the usefulness of eye blinking as a marker for central dopaminergic activity. J Psychopharmacol 18(1):109-114. https://doi.org/10.1177/0269881104042832

Van Opstal F, Van Laeken N, Verguts T, Van Dijck JP, De Vos F, Goethals I, Fias W (2014) Correlation between individual differences in striatal dopamine and in visual consciousness. Curr Biol 24(7):R265-R266. https://doi.org/10.1016/j.cub.2014.02.001

Widmann A, Schröger E, Maess B (2015) Digital filter design for electrophysiological data - a practical approach. J Neurosci Methods 250:34 46. https://doi.org/10.1016/j.jneumeth.2014.08.002

Wiecki TV, Frank MJ (2013) A computational model of inhibitory control in frontal cortex and basal ganglia. Psychol Rev 120(2):329 355. https://doi.org/10.1037/a0031542

Wise SP, Murray EA, Gerfen CR (1996) The frontal cortex-basal ganglia system in primates. Crit Rev Neurobiol 10(3-4):317-356. https:// doi.org/10.1615/CritRevNeurobiol.v10.i3-4.30

Yeterian EH, and Van Hoesen GW (1978) Cortico-striate projections in the rhesus monkey: the organization of certain cortico-caudate connections. Brain Research, 139(1), 43-63.

Yousif N, Fu RZ, Abou-El-Ela Bourquin B, Bhrugubanda V, Schultz SR, Seemungal BM (2016) Dopamine activation preserves visual motion perception despite noise interference of human V5/MT. J Neurosci 36(36):9303-9312. https://doi.org/10.1523/JNEUROSCI. 4452-15.2016

Publisher's note Springer Nature remains neutral with regard to jurisdictional claims in published maps and institutional affiliations. 